

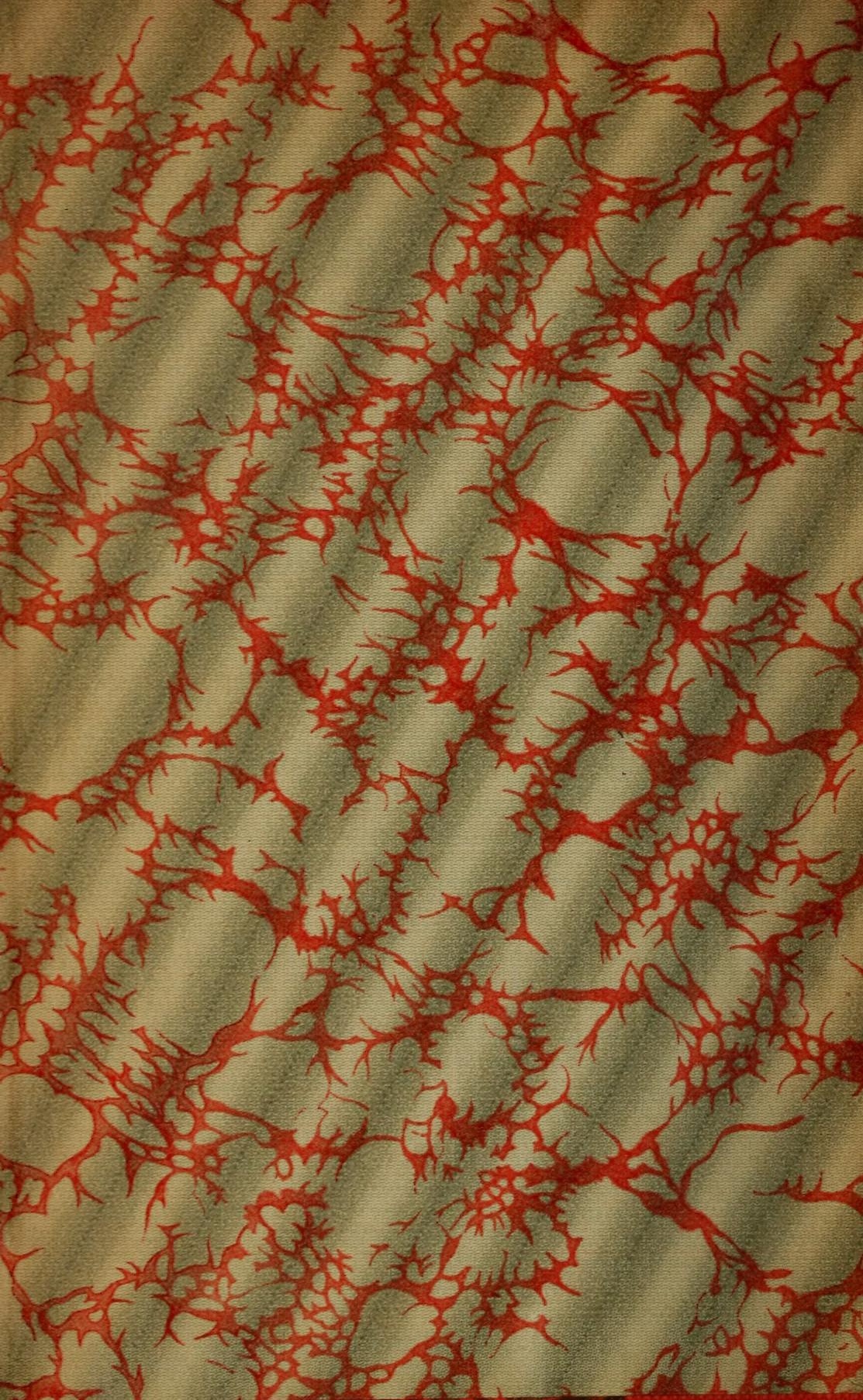




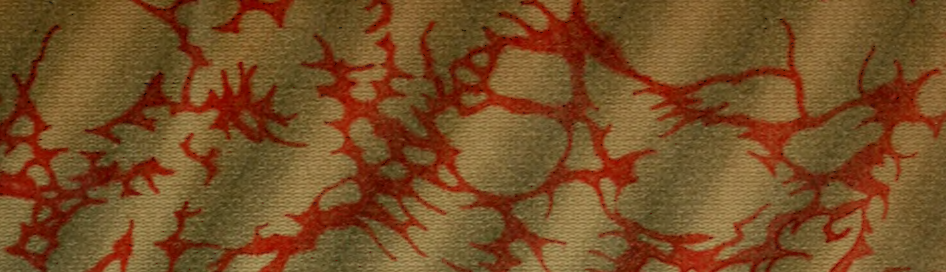

का

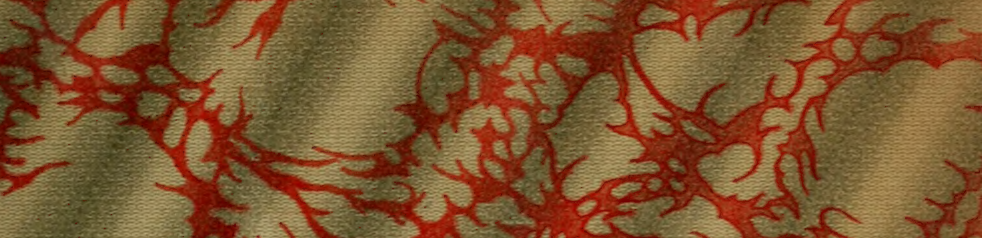

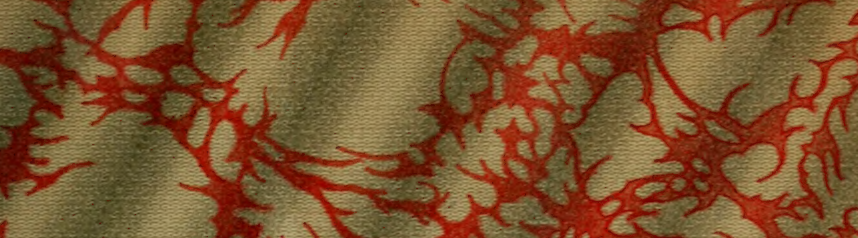

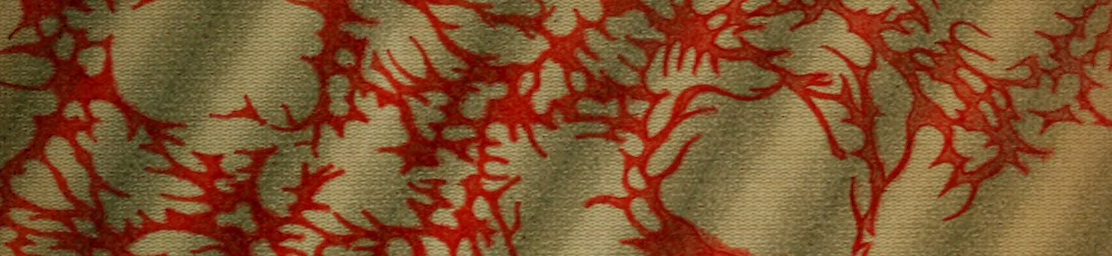

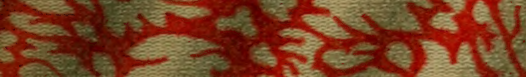

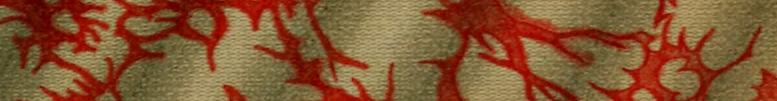

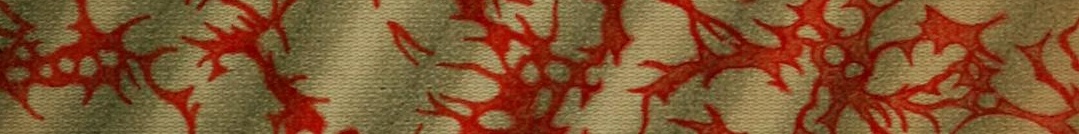

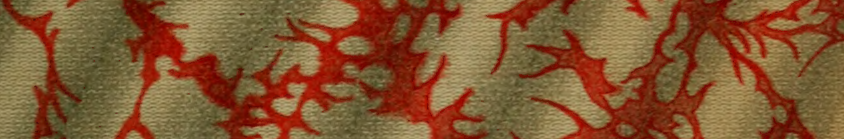

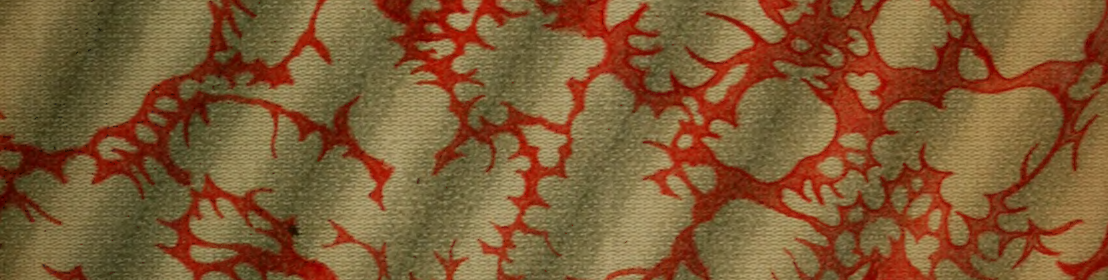

* xem tud ad arikt ) rade

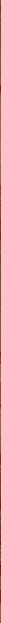




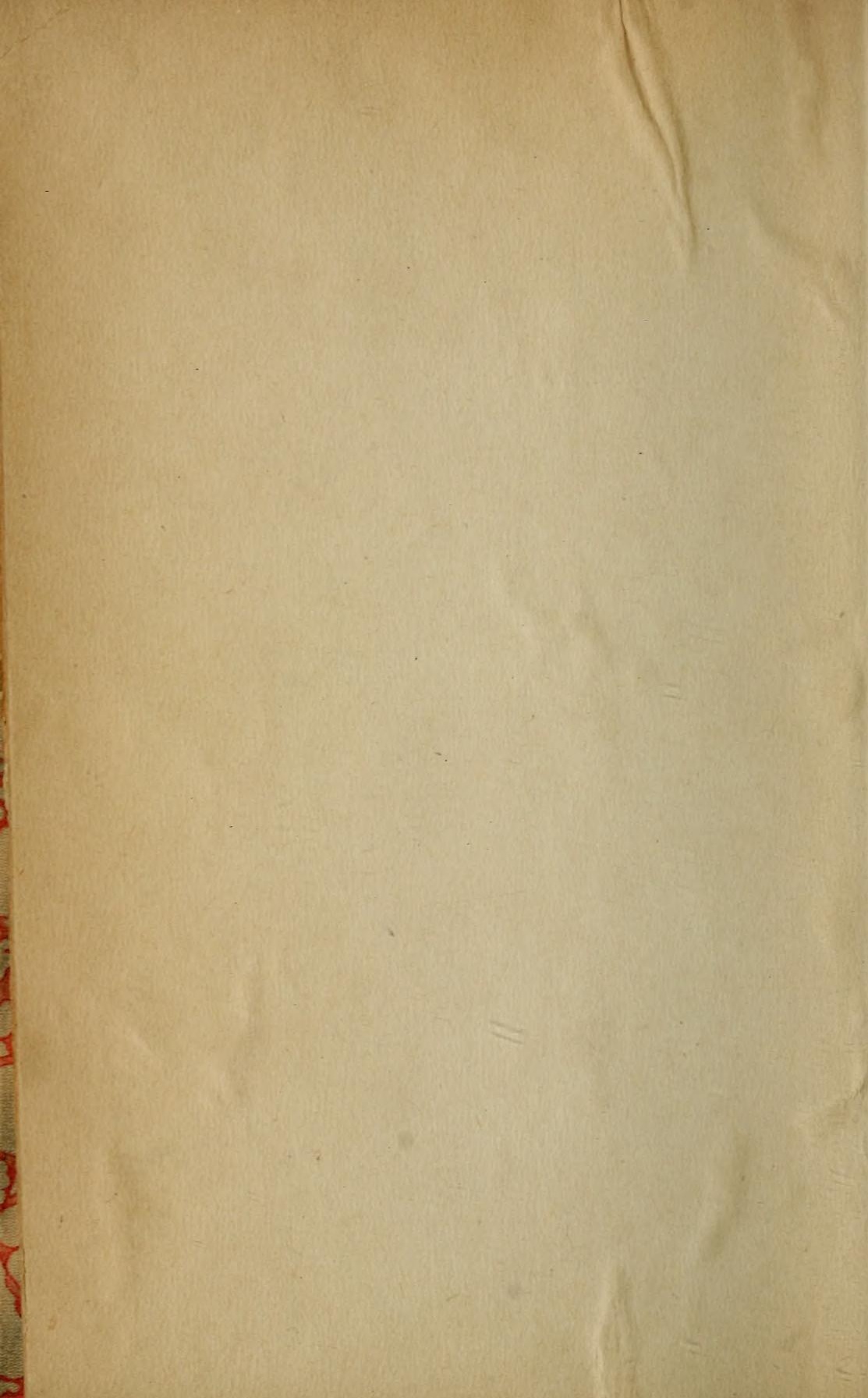



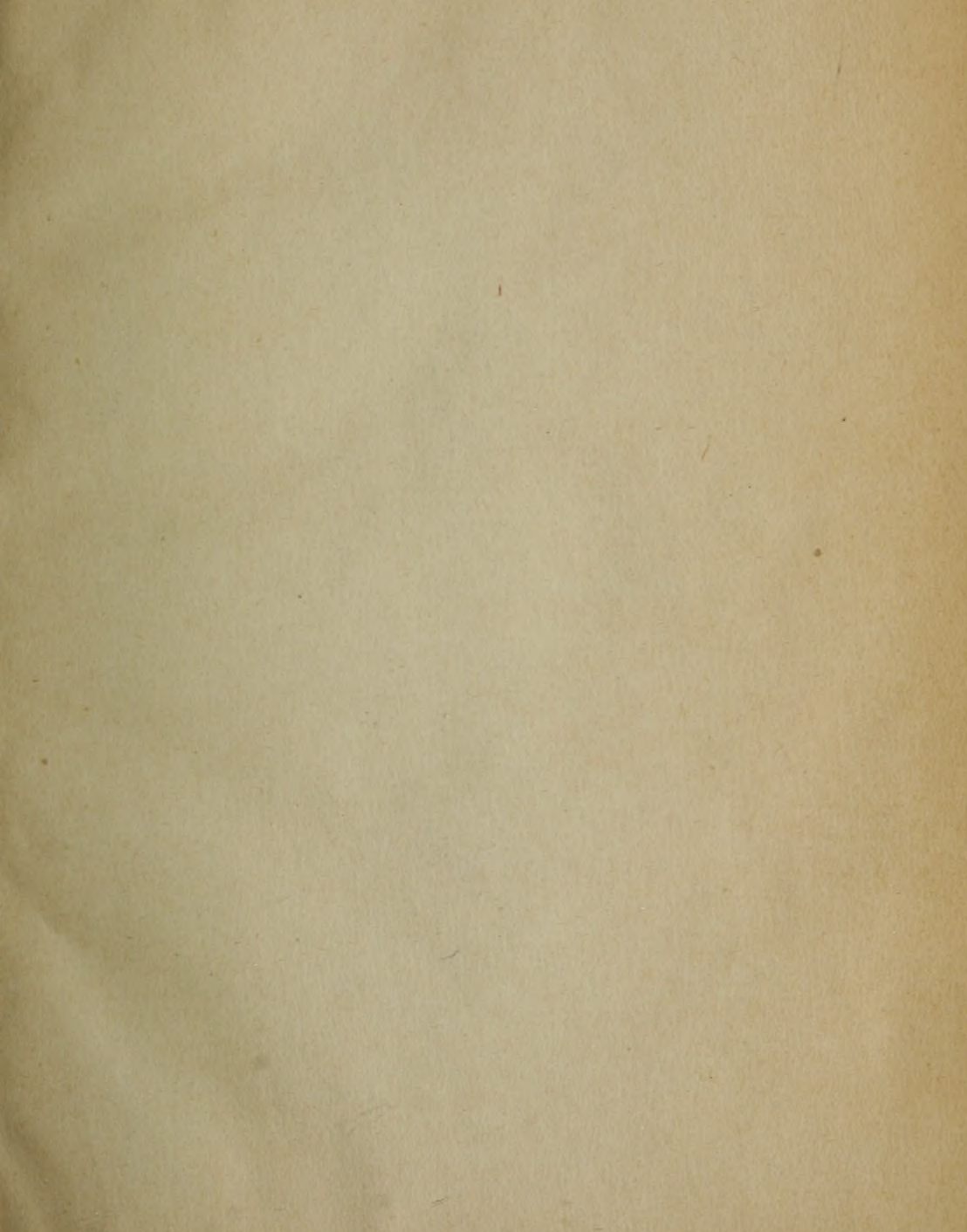

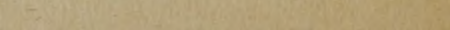





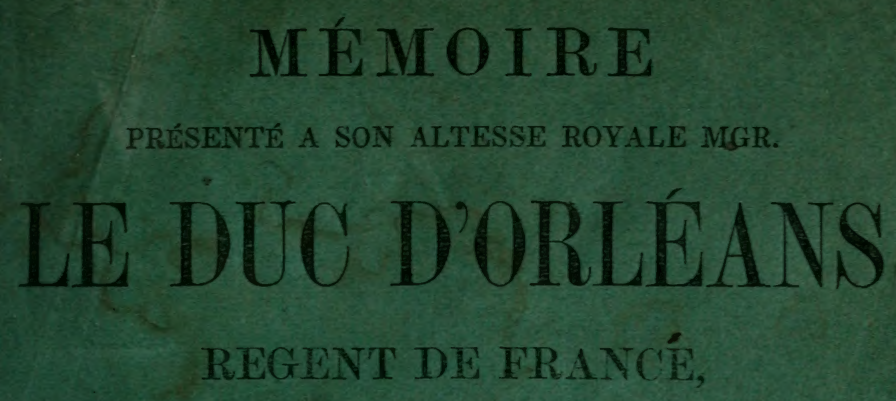

CONCERKANT LA PRECIEUSE PLANTE DU GIN-SENG DE TARTARIE,

Découverte en Amérique parle Père

\section{JOSEPH-FRANCOIS LAFITAU,} DE DA-COMPAGNTE DE JESHS,

MTSSIONNAIRE DES IROQUOTS

DU SAULT ST, LOUIS.

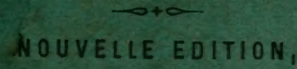

Précedé d'unte notice biogiaphique. par. M. Hospice Verrean

Prineinal de l'Ecole Nornale Jacques-Cartier et accompagné d'un portrait du Père Lafitan, d’un fac sirimile de son antographe et

de la planche représentant le gin-seng.

\section{MONTRÉAL}

IIYPOGRAPHIE DE SENECAL, DANIEL ET COMPAGNIE,

No. 4, Rue Saint Vincent,

1858. 


\section{MÉMOIRE}

PRÉSENTÉ A SON ALTESSE ROYALE MGR.

\section{LE DUC D'ORLEANS \\ RÉGEN'T DE FRANCE,}

CONCERNANT LA PRECIEUSE PLANTE DU GIN-SENG DE TARTARIE,

Découverte en Amérique par le Père $I P / \mathrm{A} / \mathrm{h}$

JOSEPH-FRANCOIS LAFITAU,

,

DE LA COMPAGNIK DR JEST:

MIISSIONNAIRE DES IROQUOT'S

DU SAULT ST. LQUIS.

NOUVELLE EDITION, / /

Précédée d'une notice biographiqne, par M. Hospice Verreau .

Principal de l'Eeole Normale Jacques-Cartier

et accompagné d'un portrait du Père Lafitau, d'uin fac simile de son autographe et

de la planche représentant le gin-seng.)
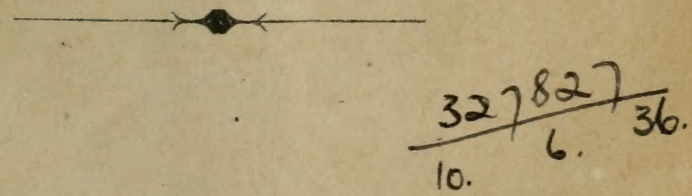

MONTRÉAL

TYPOGRAPHIE DE SENECAL, DANIEL ET COMPAGNIE,

No. 4, Rue Saint Vincent,

$18 \overline{58}$. 



\section{.}

P. Th 


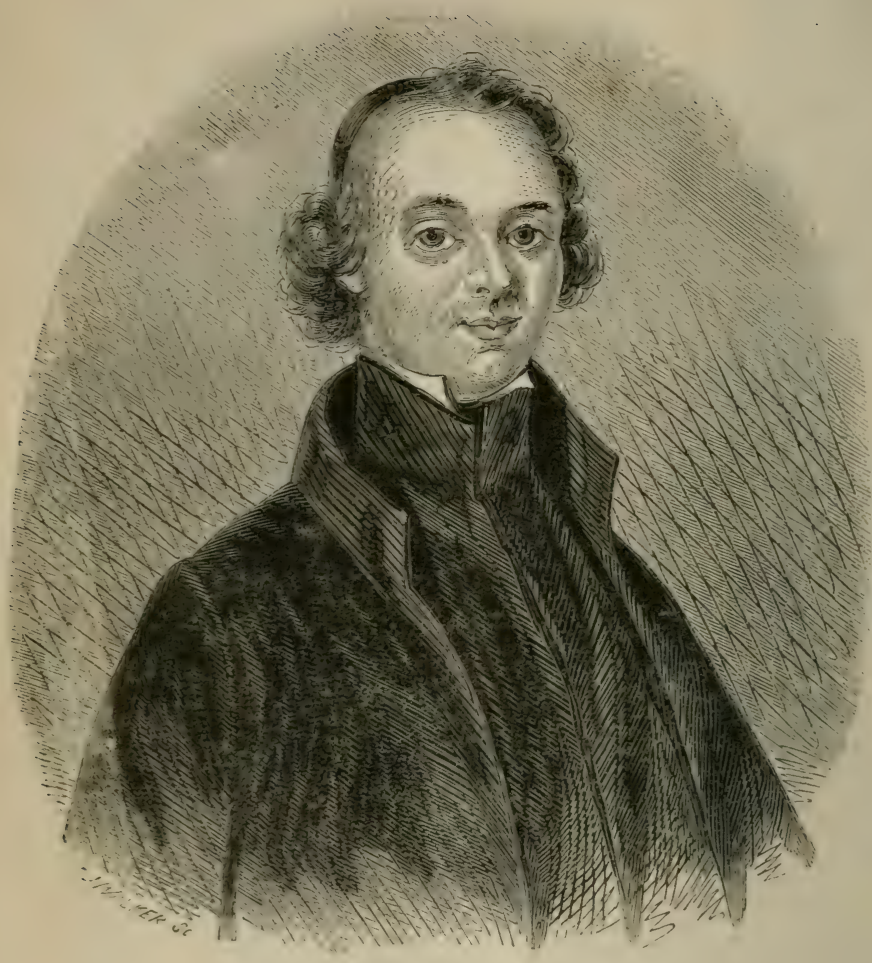

$$
\text { DS Lafitran Snifiommaire }
$$




\section{LE PERE I.AFITAU}

\section{ET LE GIN-SENG.}

L'ancien gouveruement du Canada ne fut, on commence à en -onvenir anjourd"hui, ni si indifférent au développement des ressources du pays, ni si ignorant de ses richesses géologiques et botaniques, qu'on arait paru le croire. Il est au contraire bien constaté que, tandis que l'exploration géographique de toute l'Amérique clu Nord était alors beancoup plus complète qu'elle ne l'a été juscqu'à ces clemières années, tout ce cin'il y avait d'important au point le vue gréologique avait été inciiqué et presque toutes les exploitation: itu territoire et cle ses produits commencées arec succès. Le gouvernement avait méme créé ou tavorisé diverses branches d'industrie qui ont été, depuis, complètement abandonnées, comme on pourra s'er: convaincre en pareourant l'Histoire du Canada de M. Gameau, et le Tableau des Progrès Intellectiols et Maície's du C'anada, par M. Biband, jeune.

L'histoire naturelie diz pass avait été étuliée par des homme-péciaux; et la Flore canadienne avait été décrite non seulement daus l'excellent ouvrage de Charlevoix, cont les gravures ne je céclent en rien a ce qui peut étre fait de micux de ros jours; maiencore dans plusieurs mémoire: pulliés dans les recueils des académies ou dans des lettres et relations gue l'on se disputait avec avidiré. Autant le Canadir est aujonul'hni profontément ignoré dis la France, autant alors il excitait d'intérêt.

Les Jésuites, qui ont joué un si grand róle clans la colonisation de '-Amérique, ont aussi pris une place distinguée parmi les historienet les naturalistes di noureau mome. Leurs curienses relation:uii se rémpriment actuellement à Québer, abondent en rense:cnoments et en descriptions de tout renre, et sont d'autant pirjrécieuses clue, non seulement chacine père jésuite a profité dé sepropres ouservations, mais a de plus réuni et et fait valoir celles de ses confreres. Dans une comminanté, dans un ordre religieus, rier. n'est perclu; l'obsorvateur attentif, nais qui serait peut-être inca- 
pable de faire part de ses découvertes à la postérité, trouve à côté de lui l'écrivain habile, qui se hâte de recueillir et de transmettre ses récits.

Après Charlevoix, le Père Lafitau est un des jésuites qui se sont le plus distingués comme historiens et comme naturalistes. Le Journal de l'Instruction Publique, dont les rédacteurs s'efforcent de réunir dans leur collection tout ce qui peut intéresser les amis sincères de la gloire de notre pays, commence aujourd'hui la reprocluction du Mémoire que ce savant missionnaire présenta au Due d'Orléans, régenı de France, "sur la précieuse plante du gin-seng," qu'il venait de découvrir dans les foréts du Canada, mémoire fort rare maintenant et qui, accompagné comme il l'est, d'un fac-simil: de la planche qui se trouve dans le volume publié à Paris, et d'un portrait avec antographe de l'auteur, sera pour les annateurs des souvenirs historiques du pays une véritable bonne fortune. Nous eussions aimé à joindre à ce mémoire une notice biographique que:que peu étendue ; mais, malheureusement pour nous, le Père Lafitau était du nombre de ces apôtres zélés, dont la vie se résume dans leurs travaux et dans leurs écrits, où l'homme a toujours le soin de s'effacer derrière les grandes choses qu'il accomplit.

C'est avec beancoup de peine et grâce à l'obligeance du $\mathrm{K}$. F. Martin et de MI. le Commandeur Viger, que nous avons pu réume: quelques détails que nos lecteurs jurgeront, sans-doute, bien insmifisants.

Joseph François Lafitau, naquit à Bordeaux, vers la fin du 17e siècle. Le Père Martin lui-même n'a pu nous donner l'année de sa naissance. De quelques notes qu'il vient de recueillir en Europe et qu'il a bien roulu nous communiquer, nous pouvons conclure give Lafitau étudiait la théologie à Paris, en 1710, et qu'il avait demanilé au Père-Général la faveur d'être destiné aux missions du Canadia. Un passage de son grand ouvrage, Mours des suaverges, nou: avait fait penser qu'il n'était venu dans ce pays que vers 171: e: non en 1700, comme on l'a écrit, et nous voyons aujourd'hui, cili'e?! effet, il arriva en Canada en $\mathbf{1 7 1 2}$ et qu’il fut immédiateine: envoyé à l'ancienne mission du Sault St. Louis. C'ette mission, a cette époque, offrait encore beaucoup de fatigues et certains dangerexposée comme elle l'était, aux premiers coups de l'ennemi; mai. aussi elle avait des charmes qui semblent n'avoir pas échappé au missionnaire lui-méme. La vie sauvage avec sa rude poésie, les cris de guerre, l'alarme continuelle, le cliquetis des armes presque ioujours retentissant; et puis le grand fleuve tourbillomant et allant se briser sur les écueils, les blanches maisons, les rares clocher: qui commençaient a briller dans le lointain, au milieu de la forét éclaircie et au-dessus de l'écume des flots; tout ce paysage, si nouveau et si saisissant pour eux, devait frapper vivement l'imagination des étrangers. Disons-le a notre grande honte, le Sault Si. Louis est un de ces endroits trop inconnus, ou plutót, trop méconmus de nos jours, où, à des beautés naturelles du premier ordre se ra:tachent des souvenirs hisțoriques du pius vif intérêt. Tandis que les touristes européens, comme M. Marmier et M. Ampère, viennen: 
-errer la main au pauvre prêtre de Caughnawaga (1), heureux d'apprendre quelque chose de sa bouche, nous n'allons, nous, dans ce lieu célèbre, que pour y prendre le chemin de fer et nous éloigner, à toute vapeur, de l'ancien théâtre de la foi et du courage. Cepencant, si nous entrions à la mission, on nous y montrerait peut-être *ncore le fauteuil qui a servi à Lafitau et la modeste chambre ou Charlevoix vint plus tard prier, méditer et travailler.

Ce fut dans l'ancienne mission du Sanlt, que le premier s'occupa surtout à préparer les matériaux de son grand onvrage, intitulé : "Les Mœurs des Sauvages Américains comparés aux Mwurs des premiers termps;" comme il nous l'apprend lui-même: "Pendant cinq ans, (2) dit-il, que j'ai passés dans une mission des sauvages du Canada, †ai voulu m'instruire à fond du génie et des usages de ces peuples, et j'y ai surtout profité des lumières et des connaissances d'un ancien m.ssionnaire jésuite, le Père Julien Garnier, etc. Je ne me suis pas contenté de comnaitre le caractère des sauvages et de m'informer de leurs coutumes et de leurs jratiques; j'ai cherché dans ces pratiques $\Leftrightarrow$ ce scoutumes comme des vestigges de l'antiquité la plus reculée."

Au milieu de ce travail et au moment peut-être où il y pensait le moins, il eut le bonheur, qu'il avait longtemps ambitionné, de nouver, à quelques pas de sa demeure, cetie célebre plante du gin-seng dont on commençait à parler alors en Europe (3). Tous les cétails de cette découverte sont rapportés avec une simplicité charnante dans le mémoire auquel nous renvoyons les lecteurs: ils y verront, en même temps, la description de la plante, ses vertus et Lев opinions qui partageaient les savants à son sujet. Il suffira de dire ici que le gin-seng, panax, est un genre de la famille des "raliacées. Les Chinois, les Japonais et les Tartares, le précos:isaient comme un remède universel, ce qui justifie le nom (panacée) que les savants lui ont donné (4). En Chine, il se vendait aul poids de l'argent; trois onces de ce métal pour une once de ginseng. Aussi, la découverte qu'on en fit dans nos forêts produisit presque autant d'émotion, excita presqu'autant la cupidité que le fait aujourd'hui la découverte des plus riches mines de la Californie, de l'Australie ou de la Nouvelle Calédonie. Nous citerons, à ce

(1) On écrit Caughnawaga et Cahnawaga; mais la meilleure orthosraphe pour la prononciation française est Ǩ thunuaké. D'après feu 3I. Marcoux et le y. de Lorimier, descendant des Iroquois par sa mère, ce nom signifie rapides.

(2) Comme le Père Lafitau dit qu'il resta cinq ans missionnaire, ef comme il est prouré qu'il repassa en France en 1717, il est constant qu'il vint en Canada en 1712. Du reste, nous l'arons dit en commençant, cette remarque s'accorde arec les notes du Père Martin.

(3) Bouillet place cette décourerte vers 1712: la Société Historique de Québec en 1720; mais Lafitau nous dit qu'il trouva le gin-seng en 1716. lorsque le fruit était dans sa maturité, c'est-à-dire, dans l'automne.

(4) Du grec pan tout et anekomaĩ guérir. 
sujet, notre historien M1. Garnean: "Le gin-seng que les Chinois tiraient à grand frais du nord de l'Asie, fut porté des bords du St. Laurent à Canton. Il fut trouvé excellent et vendu très cher; de sorte que bientôt une livre, qui ne valait à Québec que deux francs, y monta jusqu'à vingt-cinq francs. Il en fut exporté, une année, pour 500,000 franes. Le haut prix que cette racine avait atteint, excita une aveugle cupidité. On la cueillit au mois de mai au liet: du mois de septembre, et on la fit sècher au four au lieu de la faire -echer lentement et à l'ombre : elle ne valut plus rien aux yeux des Chinois, qui cessèrent d'en acheter. Ainsi, un commerce qui promettait de devenir une source de richesse, tomba et s'éteigni complètement en peu d'années." Ceci prouve que nos pères méritaient un peu le reproche qu'on nous adresse aujourd'hui, de vouloir recueillir presqu'avant d'avoir semé. Toujoars est-il qu'en $175^{\prime}$ on n'en exporta que pour 33,000 francs, et de ce grand commerce, il n'est resté qu'un dicton populaire que nous avons entendu plusieurs fois répéter à des vieillards dans nos campagnes: " $C$ 'est tombé, ou ça tombera comme le gin-seng."

Le commerce du gin-seng a cependant continué à se faire de I'Amérique à la Chine, é, chose étrange que nous apprend le Dictionnaire de McCulloch, les marchands anglais l'ont, pendant longtemps, acheté des négociants des Etats-Unis, l'important en transit en Angleterre et l'exjortant à la Chine tandis qu'on aurait pu l'exporter du Canada. Aujourd'hui, les Américains l'exportent directement eux-mêmes à la Chine. Depuis quarante ans une forte proportion de ce qui s'en consomme est exportée des Etats-Unis. La. Chine et le Japon sont, du reste, les seuls pays où l'on paraisse croire aux vertus de cette plante et c'est, par conséquent, le seul marché qu'on lui conraisse. Le rrin-seng s'exporte tantôt cru, tantót préparé. Il en a été découvert dans les monts Himalaya, mais son exportation à la Chine ne paraît pas avoir réussi. Cependant, la concurrence du commerce américain en a fait baisser le prix, et il ne se vend pas aussi cher que lorsque tout l'approvisiomement se faisait en Tartarie. Le gin-seng cru se vend à Canton de 60 à 70 piastres par picul (poids chinois équivalent à $133 \frac{\mathrm{g}}{\mathrm{g}}$ livres avoir du poids), et prépraré il se vend de 70 à 80 piastres. En 1852, il en a été exporté des Eta*s-Unis à la Chine 158,455 livres, équivalent a 102,703 piastres. Il ne parait point que le grin-seng de l'Amérique du Nor! soit en rien inférieur à celui de la Tartarie, et sa dépréciation pendant un certain temps, a été dû uniquement aux causes que menionne M. Garneau. On ne voit point que celui des Etats-Unis se rende moins cher que celui de la Tartarie ou du Thibet, et, dans tous les cas, celui du Canada bien préparé doit valoir an moins celui des Etats-Unis. C'est donc une branche de commerce asse\% importante encore aujourd'hui que nous avons perdue uniquement par notre faute, et qu'il ne tiendrait qu'à nous de reconquérir, puisque le gin-seng croît encore dans nos forêts aujourd'hui comme aut temps de Lafitau. La plante existe encore dans les environs même du Sault St. Louis, et M. St.-Germain, curé de St. Laurent, en a trouvé dans les bois du comté de Terrebonne.

Dans son mémoire, le Père Lafitau s'occupe surtout i'établir 
l'identité de la plante qu'il avait déeouverte avec celle qui était si fameuse à la Chine. On a nié depuis cette identité et aujourd'hui même, dans tous les dictionnaires (1), on attribue à tort au gin-seng d'Amérique une grande infériorité. Le passage suivant, d'un des mémoires publiés par la Société Littéraire et Historique de Québec, attribué à M. Querdisien Trémais par notre savant bibliographe, M. Faribault, corrobore ce que nous avons déjà dit, d'après M. Garneau, sur l'unique cause de la dépréciation de notre gin-seng a la Chine (2): "C'est ici, écrit l'auteur de ce mémoire, le lieu de dire qu'il eût peut-être été à souhaiter que la Compagnie des Indes eût eu le commerce dn gin-seng. On n'en fait usage qu'à la Chine où la Compagnie seule a le privilége d'envoyer des vaisseaux. Autrefois ce commerce était presqu'incommu en Europe, les Chinois tiraient le gin-seng de la Tartarie; ce n'est que depuis quelques années qu'on l'a découvert en Canada. Dans le commencement, il ne rs' ait que trente à quarante sols la livre, séché et trié, et la Lunipay ie ne regardant point cet objet, permit aux officiers et supercargues the ses vaisseaux de la porter à la Chine en pacotille; mais, ert 1751, s'étant aperçue que le commerce du gin-seng devenait considérable, elle défendit aux officiers et supercargues de ses vaisseaux

(1) On lit dans le Dictionnaire des Sciences et des Lettres de Bouillet (185i) :- "En Asie, où on lui fait subir une préparation à cet effet, cette racine est lirrée au cominerce transparente. La sareur en est aroatique, d'abord sucrée, enstite âcre et amère. Elle est tonique, stimuiante et réparatrice. Les Chinois, les Japonais et les Tartares la préconisent comme un remède universel, et l'empereur de la Chine s'en réserse le rnonopole. On la rendait encore, an siècle dernier, deux à trois fois son poids en argent en Chine même. On ne la trourait alors, dit-on, qu'en Tartarie, entre les 10 e et 20 e degrés de latitude est, à partir de Pékin, et lez 39 e et 47 e degrés de latitude nord. Elle ne fut apportée en Europe qu'en 1606. Le Père Lafitau rers 1712 la troura en Canada; mais /e gin-serg d'Amériquc passe pour être inférieur. Du reste, il s'en faut de beaucoup que cette plante produise dans nos climats les merveilleux effets đ̇ont parlent les asiatiquez. Peut-être la dessication, la vétusté, la ve?raoulure sont-elles pour beaucoun dans cette infériorité. On cultire mais rarement le gin-seng dans nos jardins botaniques; il s'y multiplie difficilement.

(2). Considérafions sur l'état présent du Canada, octobre 1758, dans la "Collection de mémoires et de relations sur l'histoire ancienue du Canada, d'après des manuscrits récemment obtenus des archives et bureaux pablics en France, publiés sous la direction de la société littéraire et bistorique de Québec."-Québec, W. Cowan et fils, 1840. On remarque que l'auteur écrit gin-sing. Lafitau et Charlevoix écrivent gin-seng, d'autres, ging-seng, d'autres enfin geng-seng. MicCulloch dit que les Chinois appellent cette plante yan-sam et que les Tartares l'appellent orhota. En hollandais, en allemand et en italien c'est gin-seng; dans cette dernière langue gussi gin-sem. On rerra que Lafitau insiste beaucoup sur la signification du mot chinois, qui reut dire les cuisses de l'homme, et sur celle ân nom iroquois garent-oguen, qui a le même sens. La biographie unirerselle cit que le nom chinois se prononce gin-chen et que le nom Blandchou est orkhoda. 
de s'en charger. Il valait alors douze francs en Canada, et la Compagnie l'acheta jusqu'a trente-trois franes la livre. A la Ro- chelle, alors, les négociants de cette place domèrent ordre à leurs correspondants à Québec, d'en acheier à tout prix; on en fit chercher partout sans avoir égard à la saison de le cneillir, et au tems de sécher a propos: on le mettait, au sortir de la terre, dans des fours ou à coté des poëles; ce gin-seng ainsi cueilli à contretems et mal séché, valut jusqu'a vingt-cing francs la livre à Québec, et il en sortit, en 175:, pour environ 500,000 francs. Dans ce même lemps, la Compagnie des Indes, qui pouvait se rendre ce commerce rxelusif, ne voulur point en demander le privilége; elle so contenta de ne point acheter des parieuliers le gin-seng mal conditiomié, et de prendre des mesures pour en faire cueillir dans la saison convenable et le faire sécher à propos, en le gardant à Montréal une année entière. Le parti considérable qui avait passé a Ja Rochelle resta invendn. A force de sollicitations, la Compaynie des Indes en a acheté une partie; une autre a passé en HolIande, en Angleterre et en Espagne, et ce qui en reste à la Rochelle 10 mbera en pure perte. Il est arrivé de là, que, malgré les défenses de la Compagnie, on en a chargé en contrebande dans ses vaisseaux, qu'il en est parvenu à la Chine par la voye de l'étranger, et que la quantité et la mauvaise qualité de ce gin-seng y a décrié totalement le sin-seng din Canada. La Compagnie des Indes vient de donner ordire de cesser d'en faire cueillir.

$\because$ Le gin-seng est plus on moins bon, suivant la ciualité du terrein et le temps qu'il $y$ a qu'il est en terre; mais tout le monde "onvient qu"il fant le cueillir en septembre et le faire sécher dans des greniers, sans fen. En 1752, on le cueillait en may; on le Sectalt au four nour pouvoir le faire passer la méme année; les habitants, trouvant plus de profit a chercher du gin-seng cu'à semer da blé, abandomoient leurs terres pour courir lans les bois, qui se -oint irourés incendiés, en plnsienrs endroits, par le peu de précautions qu'ils prenoient en faisant du feu.

. si la Compagnie des Inile: eut eu ce commerce exclusivement, -ile n'auroit reçu quue le gin-señ séché à propos et cueilli en septembre; tems anquel le travatix ite la Compagnie sont presque finis, et par ce moyen le gin-seng du Canada ne seroit point décrié anjom thui en Chine. Observons que cette branche de commerce esi de la nature de celles qu'il faut rechercher, jarce qu'elle donne des profits réels à l'état : le gin-seng er Canada ne coûte yue la pene de le cueillir, et la conconmation s'en fait à la Chine. Observons de plus, que ce privilége exclusif accordé à la Compagnie des Indes était analogne à celui qu'elle a déjà, et qu'il ne portoit. aucun préjudice au commerce général."

On peut conclure de ce passage que nous n'exagérons point en dikant que le gin-seng excita au Canada, chez nos pères (car il y a ie cela un siècle seulement), une fièvre assez semblable à celle que cause l'or de la Californie et des nouvelles régions aurifères de la rivière Frazer, dans ce moment. On négligeait l'agriculture et la perturbation amenée clans le pays par la chute de ce commerce, est bien indiquée, par le proverbe ou dicton que nous avons men- 
tionné. Dans l'état actuel des choses il n'y aurait rien de semblable à craindre.

Ne paraît-il point, du reste,étonnant que les populations asiatiçues aient trouvé et trouvent encore, à cette racine, des propriétés médicales si puissantes, et, qu'en Amérique et en Europe, on ne ini reconnaisse aucune de ces vertus? Il est rrai que l'énergie des substances chimiques généralement employées dans la pharmacie moderne a fait tomber dans l'insignifiance la plupart des simples; mais comment se fait-il, cependant, que la droguerie américaine, quvi fait encore ou prétend faire un si grand usage des végétaux, n'ait pas exploité darantage une plante dont les asiatiques disent tant de merveilles? Ne serait-il pas intéressant de constater avec soir leffet qu'elle peut avoir dans nos climats; aussi de déterminer J'influence qu'exercerait sur elle la culture, qui modifie quelquefois d'une si singulière manière les propriétés des végétaux? (1)

Quoiqu'il en soit, la découverte du gin-seng en Canada a suffisamment marqué dans notre histoire pour rendre mémorable le nom. cie Lafitau, illustré, du reste, par l'autres travaux. En 1717, i! repassa en France pour les affaires de la mission du Sault St. Louis, comme il le dit dans une de ses lettres. Il s'arissait, en efiet, l'obtenir de la Cour la permission de transporter le village Iroquois du Sault à l'endroit où il se trouve aujourd'hui. Les principales raisons alléguées étaient la supériorité du terrain sous le iapport de l'agriculture et les avantages que présentait le site procesé au point de vue stratégique. Il parait qu'il plaida si bien sa caise que le terrain nécessaire au nouvel établissement fut accordé Finnée suivante. Il présenta aussi un autre mémoire, qui se trouve raciuit en anglais et imprimé dans le neuvième volume de la splendide collection de documents historiques que l'Etat de NewYork fait publier actuellement sous la direction du Dr. O'Callaghan. Ce document a rapport à la traite de l'eau-de-vie et signale les $\leftarrow$ xcès et les malheurs qu'eile canse parmi les peuples sauvages.

(1) On lit ce qui suit dans un dictionnaire pharmaceutique américain a l'article gin-seng : According to the Chinese this root nourrishes and strengthens the body, checks romiting, remores hypochondriasis, and all other nerrous affections, and in short is capable of giving a vigorous tone to the system, even in old age and is a panacea for all corporal ills. It is alministered in a variety of forms and the only ill result arising from overdoses they state to be a tendency to hemorrage. Several of the Jesuits who have used the Chinese root are of opinion that many of the nroperties attributed to it are real and that it is a truly valuable remedy. On the other hand, the trials made in the United States and in Europe with the american kind prove that it is merely a gentle stimulant with some slight antispasmodic qualities. No extended observations howerer iiave becn made on it, and as regard the Chinese rariety it is difficult to come to any just conclusion for it can scarcely be possible that an article so long in use and so bighly prized, can be wholly worthless, and yet there is every reason to believe that its beneficial effects should be sttributed rather to the effects of imagination than to any extraordinary power in the root. "-Griffith's americun edition of Christison's dispensatory -Philadelphia 1848. 
Une des remarques peut-étre les plus habiles qu'il contient ent cette réflexion que, malgré la passion qu'éprouvent les sauvacres pour l'eau de feu, comme ils l'appellent, eux-mémes demandent : etre délirrés de ce fléau, et que refuser une demande anssi héroïque : 2 leur part c'est s'exposer a s'aliéner ces nations : 10. parce que les sauvages sarent très bien que l'eau-de-vie détruit leurs nations et a déjà presque détruit celle des Algonquins, et parce que le. coureurs de bois et les sauvages démoralisés par l'ivrognerie et chargés de dettes, prement refuge chez les colons anglais et travaillent ensuite a debaucher les autres sauvages et à leur montre: te chemin de Manhatte. Il cite, de plus, l'exemple des autorité. de la Nouvelle-Angleterre elle-même, qui, sur la demande du Père Pierron, missionnaire dans les cantons Iroquois, avaient promis $d a$ réprimer les abus de la rente des spiritueux. La lettre suivante d: gouverneur de Manhatte (aujourd'hui New-York) nous parait tellement intéressante que nous croyons devoir la traduire. Elie étai: adressée an Pèce Pierron, et Lafitau la citait à l'appun de soi. assertion :

"Fort James, 18 norembre 1618.

\section{"Mon Pere,}

"Votre dernière lettre me fait connaitre votre plainte secondét par celle des Chefs des Capitaines Iroquois, comme il parait plis amplement par leur requéte incluse dans ia vôtre, conceruant la très grande quantité de liqueurs que certaines gens d'Albany se permettent de vendre aux saurages, ce qui leur fait commettre de très grands excés et désordres, qui ne petwent qu'augmenter si rien n'est fait pour les prérenir. En réponse, vous apprendrez quie j’ai pris toutes les précautions possibles, et que je continuerai, pa: des amendes très rigoureusement prélevées, à empêcher qu'on ne fournisse aux sauvages l'eau-de-vie en trop grande quantité, et je suis très heureux d'apprendre que d'aussi vertueuses surgestion. zous viennent des païens à la grande holite de beaucoup de chrétiens; mais ceci doit être attribué à vos pieuses instructions et à cé qu'étant vous-même formé à la plus stricte discipline, vous leu: avez prêché la mortification antant par vos exemples que par ro. préceptes.

\section{"Francis Loviclace." "}

Cette citation, dans l'état des relatione de la France arec l'Ar:gleterre, n'était point ce que le Père Lafitau pouvait mettre de plus maladroit dans son mémoire qui, d'ailleurs, outre les motifs de seligion et d'humanité, faisait valoir habilement les intérêts nême ju commerce et de la colonisation. Son succès cependant ne fut que partiel, comme le fait voir la note suivante: "Divers mémoires ont éte envoyés au Conseil sur ce sujet, par MM. de Vaudrenil, Begon et Ramezay. Tous s'accordent sur les inconvénients di: commerce de l'eau-de-vie; mais le donnent comme nécessarre; et M. de Vaudreuil aỵant suggéé qu'il était indispensable d'alloue: deux ou trois pots d'eau-de-vie, par téte, aux sauvages des pays d'en haut qui visitent la colonie, et même de les traiter modérémen' 
au fort Frontenac ; ce sur quoi il fut délibéré en conseil le 31 mars 1716, qu'il était nécessaire de maintenir les défenses générales qui ont dejà été faites ; mais en même temps de permettre le transport de l'eau-de-vie, en petites quantités, aux endroits proposés par M. de Vaudreuil. S'il juge à propos de renouveler les ancienues défenses, il devra le faire sans en changer la teneur. Observations. -La traite de l'eau-de-vie dont se plaint le Père Lafitau est évidemment celie qui se fait dans les villes de la colonie, laquelle il est toujours nécessaire de supprimer. Fait et arrété, le ler juin 1718 - Signé L. A. de Bourbon. Le maréchal d'Estrées-Par le Conseil, La Chapelle. Et plus bas: Faire savoir à MM. de Vaudreuil et Bésron, que le Conseil a appris qu'un grand nombre de permis ont été délivrés en sus de ceux que l'on avait alloués. Défendre l'octroi d'aucun permis de ce genre sous quelque prétexte que ce soit. Accorder, une autre année, le nombre ordinaire de permis; et déclarer ensuite qu'il n'eu sera plus octroyé. Les porteurs de ces permis devront en informer les sauvages afin qu'ils apportent leurs effets. Défendre d'inclure dans les permis qui seront donnés eu dernier lieu, la permission d'emporter de l'eau-de-vie même pour l'usage des voyageurs."

Tel fut, pour le moment, le résultat des efforts de notre missionnaire; mais les intérêts de son cher troupeau n'étaient pas les seuls qui le préoccupaient. La découverte qu'il arait faite devait trop iufluer sur le commerce et la prospérilé du Canada, pour qu'il ne cherchât pas à la faire apprécier du gouvernement. Il présenta donc lui-même sa précieuse racine au Régent dont on a dû remarquer la signature au bas de l'arrêté du conseil. En l'honneur de ce prince, il appela le gin-seng du Canada: "l'auréliane du Canada" (Aureliana Canadensis) (1).

Peu de temps après, il publiait le mémoire que nous reprociuisons. Les exemplaires, nous l'avons déjà dit, en sont devenus trè rares. Il en existe un à la bibliothèque du Parlement (le second on le troisième peut-être: on sait que notre bibliothèque nationale Brûle périodiquement), et $\operatorname{Sir} \mathrm{L}$. H. Lafontaine en possède un autre, çu'il a bien voulu nous prêter et d'après lequel a lieu la réimpression actuelle (2). Cette complaisance mérite d'autant plus notre reconmaissance et celle du public, que ce livre est doublement précieux à celui qui le possède, par le fait assez singulier que c'est l'exemplaire même offert par le Père Lafitau au Marquis de Vaudreuil, alors gouverneur de la Nouvelle-France. On lit, en effet, sur la première page, ces mots en écriture très fine: "A MI. le Marquis

(1) Le Régent était, comme on sait, le Duc d'Orléans, et le nom latin d'Orléans, derenu cité sous l'empereur Aurélien, était Aurelianun.

(2) Les recherches et les généreux efforts de notre Juge-en-Chef ont déjà enrichi nos annales de précieux documents. Sans parler de ceux จุu'il a obtenus en France et de ses Observations, publiées dans les Questions Seigneuriales, les motifs de son jugement, dans la cause de Wilcos et Wilcos, méritent d'être lus par tous ceux qui s'intéressent à la partie de netre histoire qui suit imméđiatement la conquête. 
:e Taudreuil : " et M. le commandeur Viger, qui possècle plusieurs : utographes de Lanitau, entr'autres celui dont nous publions un facsimile, ne doute pas cire ces mots n'aient été tracés de la main du missionnaire.

II semble étrange qu'après avoir pris tant d'intérêt au Canada le 'Père Lafitau n'y soit point revenu finir ses jours; mais il resta en Europe quoicüil fut ar lemment réclamé par le Supérieur de Qué:ec, le rénérable Père Julieu Garnier (1). Bien que sur la liste des missionnaires de 1718 à 1719 , il soit encore porté comme attaché a la mission du Sault St. Louis, une note, nunc Romœ, indique cu'il devait se trouver alors dans la ville éternelle, où il pouvait Complèter ses études sur l'antiquité mieux que partout ailleurs. Plus ard il levint professeur de belles-lettres, poste comparativement cumble si l:on considère la grande réputation qu'il s'était acquise; mais qu'il recliercha sans doute par modestie et aussi pour pouvoir wavailler plus facilement à son grand ouvrage. Les Mceurs des vurages, tlc., terminés all mois de mai 17:22, ne parment qu'en : $: 21$ On ne sait ce qu'il faut y admirer davantage, ou cle j'exactitude de l'observateur ou de l'érudition du sarant. Les conjectures lu Père Lafitau se sont depuis changées en certitude; personne ne 'cute aujourd'hui cue l'Amérique n'ait été peuplée par l’Asie, -omme il le prétenclait. Quant aur races particulières d'où il fai-ait descendre nos sauvarges, rien dans les découvertes et les abservations postérieures ne contredit victoriensement ses opinions, uui paraissent d'ailleurs si fondées, entourées qu'elles sont non -eulement du prestige le l'érudition du texte; mais de celui que oroduisent les admirables gravures dont ses deux volumes sont més. "Il cherche à prouver, dit la Biograpiize İniverselle, que a plupart des peuples de l:Amérique viennent originairement de :es barbares cui occupèrent d'abord le continent de la Grèce et ses śles, d'où ayant envcyé de tous cótés diverses colonies pendant plusieurs siècles, ils furent obligés, enfin, d'en sortir, ayant été hassés en demier lieu par les Cadméens. Ceux, ajoute Lafitau, qui connaîtront bien les peuples barbares de l'Amérique Septentrioiale, $\mathrm{y}$ trouveront le caractere de ces Helléniens et de ces Peslashe soient ingénieux, et que ce livre n'annonce une grande connaissance de l'antiquité."

Les types des diverses divinités, les cérémonies religieuses et les instruments méme du culte chez tous les peuples dont il a scruté si -avamment les mnurs, les monuments et les coutumes, établissent, lu reste, cette illentité des traditions humaines que Lamennais avait pris pour base de son système philosophique et théologique, et que, dans son aveuglement, Dupuis avait exploitée en sens contraire ilans son Origine de tous les Cultes. Lafitau a fait parler cette ressemblance aux yeux de son lecteur dans ses belles gravures,

(1) Le Père Garnier est un de ces vétérans de la foi dont la vie méri:exait diêtre mieus connue. Il mourut, à Québec; à l'âge de 87 ans; il en arait passé 68 en Canada. 
dont les dessins paraissent avoir été tracés par lui-même, ce qui en so: serait déjà un mérite qu'il ne faudrait pas dédaigner. L'ouvrage dédié au Duc d'Orléans est digne, sous ce rapport, du goút artistique de ce prince. Il contient 41 planches, contenant chacune d'elles $u$ grand nombre de ǵravures. Le frontispice représente le Temp. dictant à l'histoire les admirables récits de l'Ancien et du Nourea'. Testament (1).

Un Dictionnaire Historique attribue au Père Lafitau une "Vie de Jean de Brienne, empereur de Constantinople," laquelle aurai vu le jour en 1727 ; mais il nous a été impossible de nous assure: de l'exactitude de cette assertion. En 1733, il publia " l'Histoire des Découvertes et des Conquétes des Portugais dans le Nourea? Monde," 4 vols. in-12. Le titre de cet ourrage est incorrect, puisque l'auteur $y$ décrit les conquêtes des Portugais en Asie et en Afrique plutôt que celles qu'ils ont faites en Amérique. A partir de cette publication on ne trouve plus le nom du Père Lafitau que dans un lettre qu'il écrivit de Paris en 1738. Ses derniers instants ne nou, sont guères plus connus que les commencements de sa vie: !'anné: même de sa mort n'est pas très certaine ; toutefois on la place géneralement en 1740. Nous avions espéré trouver sur lui quelques rentseignements précis, quelques détails dans les régistres du Sault Si. Louis ; mais la perte de ces intéressantes annales, brúlées dans l'in:cendie de l'église de St. Rézis, où elles avaient éte transportées pa: le Père Gordon, est d'autant plus irréparable qu'il n'en existe pa: même de copie au greffe.

D'un autre côté, les dictionnaires biographiques de l'Europa disent peu de chose de l'historien des vieilles races de l'Amérique : mais, en revanche, ils sont très explicites et tout particulièremen: renseignés à l'égard d'un de ses cousins, évêque de Sisteron, qui, aux yeux de l'histoire, a le tort d'avoir été l'ami sinon la créature du cardinal Dubois (2).

(1) Les exemplaires de cet ourrage sont devenus assez rares et disperdieus. Il en existe plusieurz dans le pars. Celui diu commandeur Vige: est enrichi des notes précieuses de Mi. Joseph Harcoux, missionnaire deIroquois de St. Régis, puis du Sault St. Louis, de 1813 à 1855, c'est-àdire pendant 42 ans. Sarant philologue, il composa une grammaire et u: dictionnaire de la langue iroquoise, et plusieurs autres ourrages encorinédits. Voir les Lettres sur l'Amériçue de M. Marmier, et la Promenad. en Amérique de M. Ampère.

(2) Pierre François Lafitau, érêque de Sisteron, naquit à Bordeaus: en 1685 , d'un courtier de vin, et dut sa fortune à son esprit. Il entr: fort jeune chez les jésuites et s'y distingua par son talent pour la chaire Ayant été envoyé à Rome au sujet des disputes élerées par les jansénistes contre la bulle Unigenitus, il plut à Clément XI. Devenu érêque. il prit une part très active à la lutte prolongée entre Port-Royal et le: jésuites. Il publia plusieurs ourrages de polémique et plusieurs mandements. Ses ourrages sont: "Histoire de la Constitution Unigenitus; 1757 et 1758,2 vols. in-12; "Réfutation des anecdotes ou mémoire: secrets sur l'acceptation de la bulle Unigenitus par Villefort," 3 rols in-12 ; "Histoire de Clément XI," 2 vols. in-12 ; "Sermons," 4 rols. in- 
Grâce, cependant, à un portrait qu'un homme, qu'il faut toujours nommer quand il s'agit d'antiquités canadiennes, M. Viger, a tiré ie l'oubli, nous pouvons donner à nos lecteurs une idée assez précise de la personne du célèbre missionnaire qui fait l'objet de cette notice. (1)

Le Père Lafitan était de taille ordinaire, il avait les traits de la figure fins et délicats, le teint blanc et coloré. Son front, ses yeux et toute l'expression de sa physionomie, indiquaient une vive et pénétrante intelligence. Sa contenance devait être pleine de noblesse et d'une douce fermeté. En un mot, il nous apparait comme un de ces hommes d'élite qui peuvent renoncer à la gloire humaine; mais que eette gloire va couronner partout, dans la cabane du sauvag̣e, dans le désert, tout aussi bien que sur un théâtre plus élevé.

Hospice. Verreat.

12: "La Tie et les Mystères de la Ste. Vierge," 2 rols in-12, et plusieurs ]:tits currages ascétiques. Il mournt en 1604 , à 70 ans, au château de Lurs, qui appartenait aux érêques de Sisteron.-Dict. Hist. de Filler.

(1) Le portrait que nous ofrrons à nos lecteurs était, ainsi que celui de Charleroix, à la mission du Sault St. Louis, où personne, sauf M. Mrarcoux, n’anrait pu les ilentifier, ce qu’il lui était facile de faire par la tradition transmise de missionuaire en missionnaire. Le commandeur Tiger les fit restaurer et copier, par M. Duncan, pour son riche album. Je portrait de Charlevoix a été anssi reprodnit par le pinceau de $\mathrm{Xi.}$ Antoine Plamonion, pour la cabine du vapeur qui portait le nom de Thistorien de la Nouvelle-France. Cette toile a clu périr ave le vais. seau, brûlé il y a quelques années.

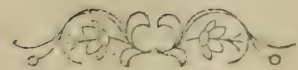




\title{
MEMOIRE
}

PRÉSENTÉ A SON ALTESSE ROYALE MGR.

\section{LE DUC D'ORLEANS, REGGENT DE FRANCE,}

\author{
CONCERAANT LA PRECIEUSE PLANTE DU GIN-SEN( DE TAR'TARIE, \\ DECOUVERTE EN AMERIQUE PAR \\ LE PERE JOSEPH-FRAXCOIS LAFITAT DE LA CONPAGIIF: \\ DE JESUS, MISSIONNAIRE DU SALLT ST, LOUIS.
}

\section{MoNSEIGNeur,}

Les ordres que Votre Altesse Royale envoya a M. Begron, (1) intendant du Canada, dès qu'Elle commença a prendre le soir in royaume, qu il ent a contribuer à enrichii la botanique, et at avoriser ceux qui s'y oceuperaient, ont été, ce semble, sccondé.s hu ciel par une découverte ntile. Dans ce temps-la même, je rouvai dans ies forets de la Nouvelle-France le Gin-seng de. 'Tartares, si estimé à la Chine. Je regardai un évènement si henseux, comme une récompense de ce zèle que Totre Altrsse Royale ent dès l'cnfance pour perfectiomer et pour faire fleurir les arts.

A la Chine, Monseigneur, il n'est point le plante qu'oir puisse whuarer an Gin-seng. Javone que je me sentis arróablement tatte de cente idée quand j'en eus déconvert en Canada. Ma joj.: "nt plus srande encore lorsque je rélléchis que ma désourerte su. strait pas tout-à-fait indiférente à un prince éralement attentit is procurer l'avancement des lettres et l'avantage des peuñes.

A la vérité, j'ai longtemps apprénendé d'interrompre les soinimportants, que donne à Y. A. R. le gouvernement d'un grant vovaume, et de détoumer son attention sur de petits objets. Enfin, fai un qu'un esprit, supérieur comme le rótre, l'est jamais assę atigué des afiaires sérieuses, pour négliger entièrement les minuties méne de littérature qui peuvent produire de l'utilité an public.

(2) M. Jagron (Michel) fut intendiant du Canada le 31 mars 1710 : meis il ne rint su pars quen 1712 . Il fut remnlacé le 2 seniembre 1726 1.a. M. C. T. Dupuy et partit de Cuébec, le 19 octubre suivant. (M. S. i: Commandeur Viger.) 
Dans cette persuasion, j'ai pris d'abord la liberté de lui faire présenter la plante que j'avais découverte. L'honneur que j'ai eu de la lui présenter moi-même, et la bonté qu'Elle a eue de ne pas dédaigner ce fruit de mes recherches, me donne aujourd'hui la hardiesse de rendre publiques mes remarques sur cette plante sons les auspices et sous la protection de V. A. R.

Je n'avais jamais entendu parler du Gin-seng étant en France. Cependant cette fameuse racine était déjà connue en Europe depuis plusieurs années, par les relations des Pères de notre compagnie, qui ont été les premiers à en parler. C'est ce qu'on peut voir dans l'atlas chinois du Père Martini, dans l'histoire naturelle du Père Eusèbe de Nieremberg, et dans la Chine illustrée du célèbre Père Kirker. Les vaisseaux français et hollandais qui nous l'ont apporté? depuis, en ont rendu la connaissance plus certaine.

Ce fut donc par un pur hazard, que je commençai pour la première fois de connaitre le Gin-senir. J'étais descendu à Québec pour les affaires de notre mission, au mois d'octobre de l'année 1715.

On a coutume de nous envoyer toutes les années un recueil delettres édifiantes des missionnaires de notre compagnie, qui travailLent en divers lieux du monde au salut du prochain. Ces lettres sont pour nous, qui nous trouvons dans les mêmes fonctions de zèle, un puissant motif de soutenir avec constance les travaux pénibles de nos missions. Rien en effet n'est plus capable d'adoucir nos peines, et de nous animer, que l'exemple de ceux de nos Pères qui, se trouvant dans la méme sitnation que nons, paraissent compter pour rien toutes leurs fatigues, et s'estiment heureus, quand il a plu au Seigneur de domner quelque suceès à l'Evangile ou'ils prêchent, ou les consoler des obstacles et des traverses qui endent leurs travaux stériles. Parmi ces lettres il y en a aussi de curieuses qui concernent les diverzes matières qui ont rapport aux sciences et aux beaux arts, et qui souvent sont des clécouvertes utile, pour le bien de l'état et des colonies. Etant done à Québec, le dixième recieil de ces lettres me tomba entre les mains; j'y loarec plaisir celles du Pere Jartoux. J'y trouvai une description exacte de la plante du Gin-seng, qu'il avait cu lieu d'examirer dans un voyage qu'il avait fait en Tartarie, l'an 1709.

L'empereur de la Chine l'y avait envoyé pour y faire la carte din pays. Îl arriva qu'au méme temps un corps de dix mille Tartareétait occupé à chercher le Gin-seng par l'ordre du même prince cui par tribut en retire deux onces de chaque Tartare, et qui achète d'eux le reste ail poids de l'argent fin. Cependant ce qu': en paye n'est que la quatrieme partie de ce qu'il le fait valoir dans son einpire, où il est vendu en son nom.

Pour annoncer les vérités de notre religın à des peuples barlıres, et leur faire goûter une morale bien opposée à la corruption de :eurs cœurs, il faut auparavant les gagner et s'insinuer dans leur. esprits en leur devenant nécessaire. Plusieurs de nos missionnaire:ont réussi en différents endroits par quelque teinture qu'ils avaient: de la médecine. Je savais qu'en travaillant à guérir les maladiedu corps ils avaient été assez heureux pour ouvrir à plusieurs le. 
yeux de !'ame. Ils se sont souvent servi de ce moyen pour bapti-e" plusieurs enfants moribonds, sous prétexte de leur donner quelque remède. Je m'appliquois done d'autant plus sérieusement a la médecine, que les saurages en sont très curieux, que quoiqu'ils aient de très bons remèdes, ils se servent encore plus volontierdes nótres, et les employent préférablement aux leurs. Je me sentais en particulier du cront pour la connaissance des plantes. cest ce me fit lire la léttre du Père Jantonx, par préférence aux antres leitres du même recueil. En parconrant cette lettre, et tombant sur l'end!oit où eo Pére dit, ell parlant de la nature du sol où croît le Gin-seng, que s'il s"en trouve quelqu'autre part du monde, ce doit être principalement en Canada, dont les forêts et les montagnes, anl rapport de cens mui y ont demeuré, sont assez semblables a celles le la Tartarie. Je sentis ma curiosité encore plus piquée par l'espérance de le découvrir dans la Nouvelle France.

Cette espérance était pourtant assez faible, et fi: peu d'impression sur moi. Je ne retirai même de la lettre qu'une illée comfuse et très imparfaite de la plante. Les occupations que jeus pendant l'hyver, qui est fort long et fort rude en Canada, acheverent presque de l'effacer. Ce ne fut qu'au printemps qu'étant obligé de passer sonvent par les bois, je sentis renaitre en moi l'envie de faire cette découverte, à la vue d'une multitude prodigieuse d'herbes dont ces iorêts sont remplies, et qui attiraient alors tonte mon attention. Je tâchai done de rappeler les idées que je m’en étais formé. Je parlai a plusieurs sauvages. Je leur dépeignis la plante de la manière que je pus. Ils me firent espérer que je pourrais en effet la découvrir.

La nécessité a rendu les sauvages médecins et herboristes; ils recherchent les plantes arec curiosité, et les éprouvent toutes; de sorte que sans le secours d'une physique bien raisonnée, ils ont trouvé par un long usage, qui leur tient lieu de science, bien des remèdes nécessaires à leurs maux. Outre les remèdes généraux, chacun a les siens en particulier, dont il est fort jaloux. En effet, rien n'est plus capable de les accréditer parmi eux que la qualité de bons médecins. Il faut aroner qu'ils ont des forêts admirables, pour des maladies dont notre médecine ne guérit point. Ils se traitent à la vérité un peu rudement, et dosent leurs purgatifs et leurs vomitifs comme pour des chevaux; mais ils excellent dans la guérison de toute sorte de plaies et de fractures, qu'ils traitent avec une patience extrême, et avec une délicatesse d'autant plus merveilleuse que jamais ils n'y employent le fer. Ils guérisent leurs malades en peu de temps, par la propreté qu'ils entretiennent dans une plaie, elle puiäit toujours fraîche, et les remèdes qu'ils y appliquent sont simples, naturels et de peu d'apprêts.

Les Français, dans ce pays-là, conviennent qu'ils l'emportent sur nous en cette matiere. J'ai vu moi-même des cures surprenantes. Les missionnaires qui sont toujours avec les sauvages, qui ont toute leur confiance, et qui parlent communément leur langue comme eux-mêmes, sont presque les seuls en état de tirer d'eux des secrets dont le public pourrait profiter. Cependant, ils ne paraissent pas y avoir pensé jusqu'à présent. Aussi, n'ont-ils pas été aussi heureux en découvertes que nos missionnaires du Pérou et du Brésil. Je 
m'imagine qu'ils ont été détournés par la crainte de paraître approuver par leurs recherches, les superstitions des jongleurs ou des médecins, qui dans les commencements te l'établissement de la colonie, étaient le plus grand obstacle qu'ils trouvaient à la prédication de l'Evangile.

Les questions que j'avais faites aux sauvages sur le Gin-seng ne m'avancèrent pas beaucoup. Je puis dire qu'elles ne me profiterent qu'autant qu' lles me domnèrent lieu de faire d'autres découvertes que j'espère perfectionmer quand je serai de retour à ma mission. i'ose me flatter que je pourrai donner dans la suite des connaissances au public, qui feront plaisir à cenx qui aiment la botanique, et dont notre médecine pourra tirer quelque secours. (1)

Ayant passé près de trois mois à chercher le Gin-seng inutilement, le hazard me le montra quand j'y pensais le moins, assez près d'une maison que je faisais bâtir. Il était alors dans sa matnrité ; la couleur vermeille de son fruit arrêta ma vue. Je ne le considérai pas longtemps sans soupçonner que ce pouvait être la plante que je cherchais. L'ayant arrachée avec empressement, je la portai plein de joie a une sauvagesse que j'avais employée pour la chercher de son côté. Elle la reconnut d'abord pour l'un de leurs remèdes ordinaires, dont elle me dit sur le champ l'usage que les sanvages en faisaient. Sur le rapport que je lui fis de l'estime qu'on en faisait à la Chine, elle se guérit dès le lendernain d'une fièvre intermittente qui la tourmentait depuis que! ques mois. Elle n'y fit point d'autre préparation que de boire l'eau froide où avaient trempé quelques-unes de ces racines brisées entre deux epierres. Elle fit clepuis deux fois la méme chose, et se guérit chaque fois dès le même jour.

Quelque présomption que j'eusse que la plante était du Gin-seng, je n'osais pourtant rien assurer n'ayant que des idées confuses de ja lettre du Père Jartoux, que je n'avais pas en main, et dont l'exemplaire était à Québec. Je pris done le parti de faire une descripion exacte de la plaute trouvée en Canada; je l'envoyai à Québece i un homme intelligent (2), afin qu'il la confrontât avec la lettre ef avec la planche gravée, qui represente le Gin-seng de la Chine.

On n'eut pas plutót reçu ma lettre, qu'on partit pour Montréal ef. qu'on se rendit a notre mission, qui n'en est qu'à trois lienes. La personne liabile et moi parcourumes les bois, ou je lui laissai le plaioir de la découvrir elle-même. Nos recherches ne furent pas lougues. Quand nous ell eumes ramassé divers pieds, nous allâme* les confronter avec le livie dans une cabanne.

A la vue seule de 1. planche, les sauvages recommurent lear piante du Canada. Et comme nous en avions en mains les diffé-

(1) On roit par ce passage que le Père conservait lesploir de revenir all Canada. Conme il demeura en France, nous ne devong pas être surpris s'il ne s'est plus occupé de ces découvertes.

(2) Cet homme intelligent, que le Pere re nomme fits, ne serait-il pa: Michel Samazin, médecin du lioi et membre correspontant de l'Académis il-s Sciences, célebre en Cauada par ses connaissances et par sez travans? 


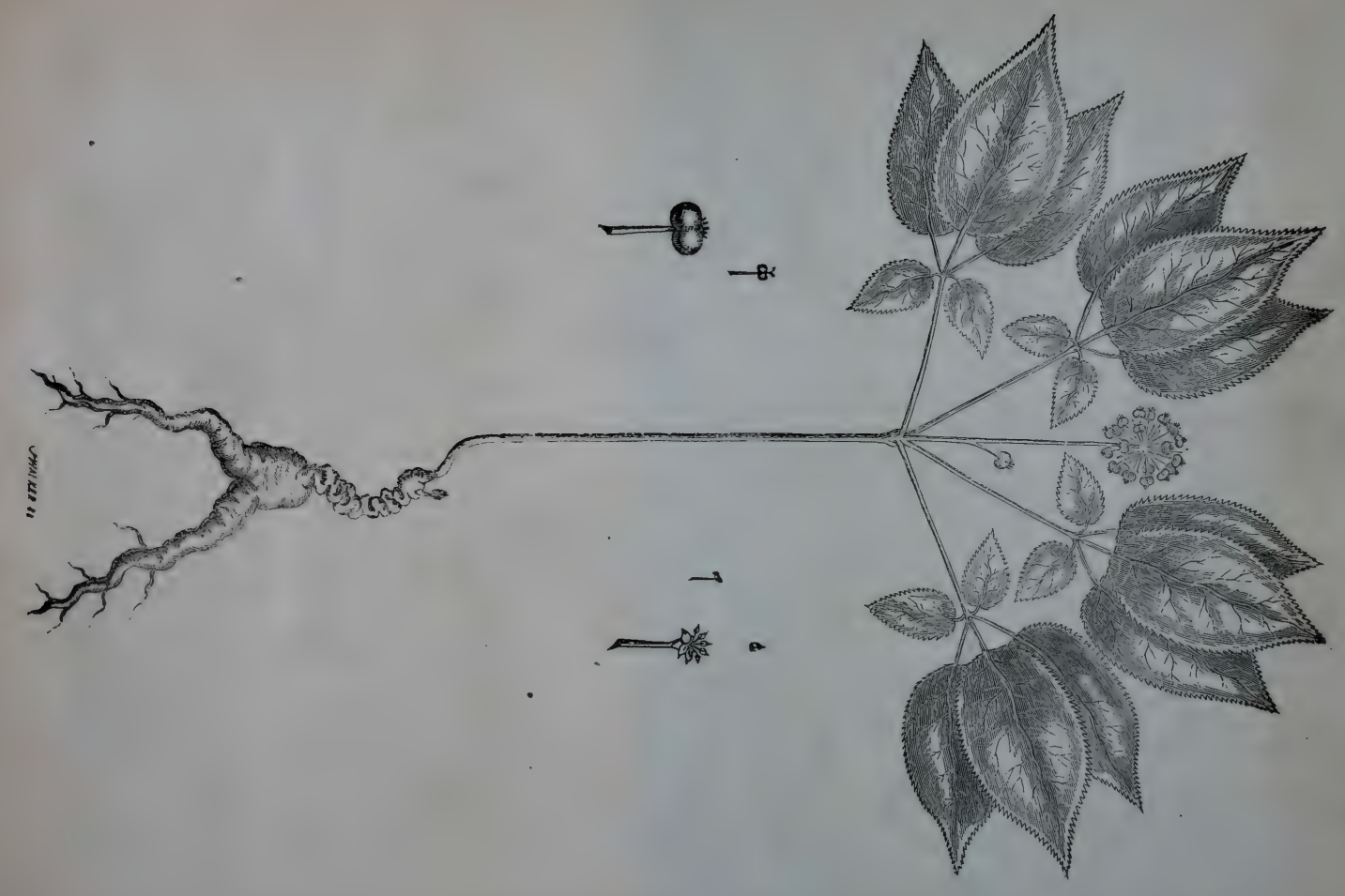



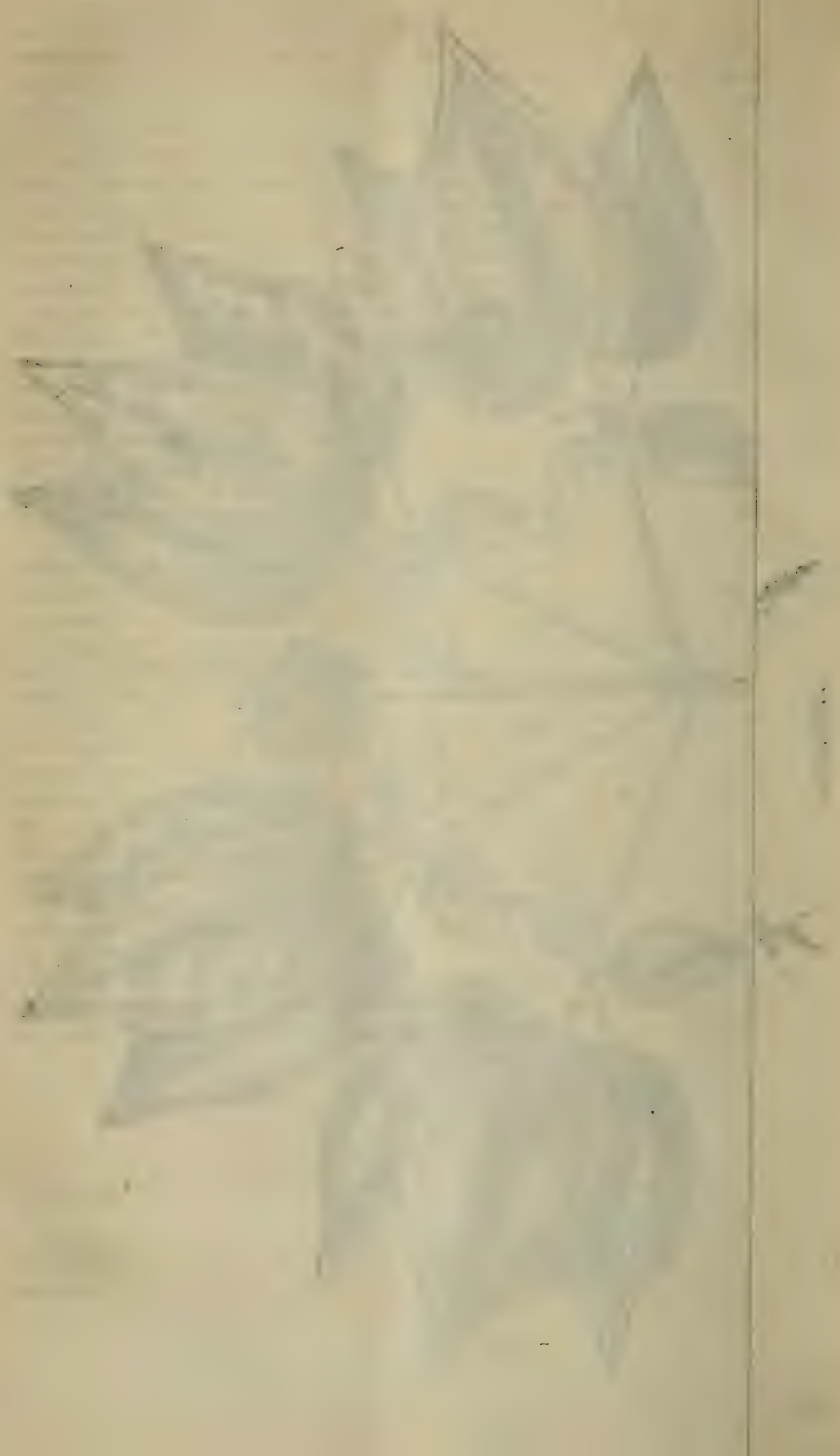
rentes espèces. nous oûmes le plaisir de voir une description si exacte et une si juste proportion avec la plante, qu'il n'y manquait fas la moindre circonstance dont nous n'eussions la preuve devant les yeux.

Ma surprise fut extrême, quand sur la fin de la lettre du Père Jartoux, entendant l'explication du mot chinois qui signifie ressemblance de l'homme, ou comme l'explique le traducteur du Père Kirker, cuisses de l'homme, je m'apperçus que le mot iroquois gưrent-oguen (1) arait la même signification. En effet, garent-ogrsen est un mot composé d'orenta, qui signifie les cuises et les jambes, et d'oguen, qui veut dire deux choses séparees. Faisant alors la même réflexion que le Père Jartoux sur la bizarrerie de ce nom, qui n'a été donné que sur une ressemblance fort imparfaite, qui ne se irouve point dans plusieurs plantes de cette espèce, et qui se rencontre dans plusieurs antres d'espèces fort différentes, je ne puz n'empêcher de conclure que la même signification n'avait pu être anpliquée au mot chinois et au mot iroquois sans une communicatiun d'idées, et par conséquent de personnes. Par là je fus confirmé dans l'opinion que j'arais déjà et qui est fondée sur d'autres préjug'és, que l'Amérique ue faisait qu'un même continent avec l'Asie, a qui elle s'unit par la Tartarie au nord de la Chine. (2)

Quoique le Pére Jartonx ait donné, comme je l'ai dit, une description exacte et fort détaillée de cette plante, je ne laisserai pas the la donner ici pour y ajouter les observations que j'y ai faites. La crande quantité qui m'en a passé par lés mains, donnera de la créance à mon récit.

La racine a cleux choses qu'il faut observer: une espèce de navet qui en fait le corps, et le collet du navet même.

Le navet gui fait le corps de la racine est peu différent de noz savets ordinaires. Quand on l'a lavé il paraît blanchâtre en dehors et un peu raboteux. (Wuand on l'a coupé en travers, on voit un cercle formé par la première écorce qui est assez épaisse, et un corps ligneux fort blanc, qui représente un soleil par plusieurs lignes droites tirées du ceiitre au parenchyme, leçuel en fait la circonférence. La racine en séchant jaunit un peu, mais le dedans de la racine coupée en long on en travers conserve toujours parfaitement sa blancheur.

C'es navets sont différens les uns des autres. 11 y en a qui ont beaucoup de fibres et d'autres qui n'en ont point ou presque point. Quelquues-uns sont sirnples, longs et unis sans se diviser; d'autres

M. Dufrène pense que le véritable nom iroquois du gin-seng est Te karent: Gera. La particule $T$ e indique la dualité et doit toujours s'emplcyer lor:quelle parle de deux choses; mais dans une bouche iroquoise, la pronorciation cle ce mot est tres douce Tharent-olien. Quand au changement a a $\mathrm{g}$ en $h$; on le troure assez sourent dans les différentes dialectes ircquois.

(2) Il y a suns doute plus qu'une simple consonnance entre liroquois grentu et les muts orlott, orlitoda, employés, le premier par les Tartares; le second par les Mantchoux pour désigner le gin-seng. 
an contraire se distribuent en denx on trois branches. Alors ils i:e représentent pas mal le corps d'un homme depuis la ceinture ez has, ce qui lui a fait domer le nom de Gin-seng on de Crarentogüen.

Le collet de la racine est un tissu tortueux de nocuds où sont imprimés obliquement et alternativement tantôt d'un cóté tantôt dé l'autre, les restiges des différentes tiges qu'elle a enes, et qui marquent ainsi l'age de cette plante, qui ne prorluit un'tme tige par ar.

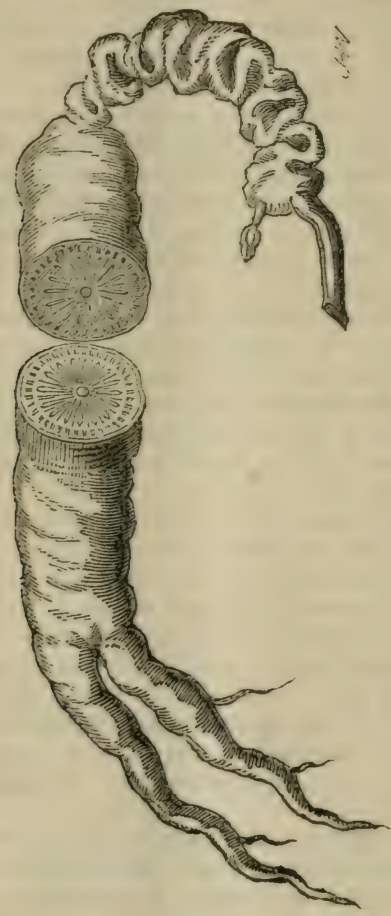

J'ai trouvé dans plusieurs le reste cles tiges des deux ou trois années précédentes au-dessous de celles de l'année qui court, et au-dessus de celle-ci on voit se former en automne celle qui doit pousser le printemps d'après. En comptant les nœuds j'ai vu des racines qui marquaient près de cent ans.

On voit souvent sortir du collet d'espace en espace deux ou trois de ces navets simples, aussi bien que quelques fibres, ce qui peut étre l'effet d'une trop grande abondance de sève, qui trouvant une issue par le collet, forme une nouvelle racine, ne pouvant se répardre et circuler toute entière dans la tige. On voit quelquefois sortir 
an nouveau collet à cóté du premier, qui clevient alors stérile, cette plante n'ayant jamais qu'une seule tige.

La tige sort du collet environ deux ou trois pouces avant dans la terre. La difñculté qu'elle trouve à la percer et à se faire jour la rranchit (1) un peu; mais dès qu'e'le en est sortie, elle s'élève à la Thauteur d'un pied ou mème de plus d'un pied. Elle est ordinairement fort droite et assez unie.

Tandis qu'elle est lans la terre, la terre Ja blanchit; mais dès cu'elle arrive au grant air, elle se colore d'un beau vert glacé d'un rouge amarante qui se confond et se perl aussi bien que ce vert foncé, à mesure qu'elle approche du nœud.

Ce noud se forme au sommet de la tige, et il est le centre de trois ou quatre branches, que je nomme ainsi, pour me conformer à la manière de parler du Père Jartoux, qui appelle branches ce qui n'est proprement que les queues des feuilles. Ces branches s'étendant horizontalement et s'écartant égalernent les unes des autres, forment avec leur's feuilies tine especce de parasol renversé et assez arrondi. La conleur d'arrarante et de rert se renourelle an noud, et se dégracie insensiblement en approchant des feuilles.

Quelques-unes de ces tiges n'ont que denx branches. Il s'en trouve, au rapport cłu Père Jartoux, qui en ont cinq ou même sept. Je n'en ai point vu le si touffues en Canala. Les plus communes sont de trois ou quatre branches. Celles qui en portent quatre sont les plus belles et les plus agréables à l'œil.

Chaque branche contient ring feuilles inégales, et qui partent toutes l'un même centre, elless'étendent en forme cl'une main ouverte. La ienille du milieu est plus grancle que les deux voisines, et celles-ci sont plus grancles que les ceux plus basses. Le Père Jartoux dit qu'on ne voit jamais moins de cinq fetiiles a chaque branche; j'en ai vu qui n'en avaient que quatre ou même que trois. Il est cependant facile de voir que e"est alors un dérangement prochit par une cause étrangère un par la faiblesse de la plante, qui n'a pas eu assez de suc pour se développer toute entière. et qui est devenue monstrueuse faute d'aliment.

Les feuilles de la nourelle plante sont oblongues, dentelées, et d'une finesse extrène: elles se retrécissent et s'allongent vers la. pointe. Le dessus de la feuille est d'un vert foneé, le revers en est plus blanchâtre, plus uni et fo:t transparent. Les fibres qui se répandent sur tonte sa superficie sont plus saillantes sur ce revers, et on $\mathrm{y}$ distingue de petits poils blanc's et droits qui s'élèvent de distanee en distance. Il faut cependant beaucoup d'attention pour ies observer, et on he les apperçois bien ciu'en jes plaçant horizontalement entre l'wil et la lumière.

Les couleurs de la tige et des branches s'éclaircissent à mesure cite la plante approche de sa maturité ; le vert se chnnge en un blanc terne, le rouge n'est plus si foncé, et dans l'automne lu: ienilles en séchant prennent ou la couleur ordinaire de la feuille inorte, ou une conleur vinetise pareille à celle des feuilles de la vigne rampante.

(1) La force à se courber. 
Au centre du nœud où se forment les branches, s'élève un pédicule d'environ cinq à six pouces, qui parait être la continuation de la première tige, et soutient un bouquet de petites fleurs. En son temps, de très beaux fruits leur succèdent. Ils sont entés par leur base sur autant de petits filets ou pédicules particuliers de la longueur d'un pouce et déliés à proportion, écartés à égale distance len uns des autres en forme sphérique. Ils composent une ombrelle ḋ pou pres semblable par sa figure à celle du lierre, mais bien différente par la beauté de son fruit. Ces pédicules sont d'une coulen: plus vineuse que le reste.

Je ne pus examiner la fleur du garent-oguen en 1716, que je le découvris; le fruit était alors dans sa maturité. Ainsi, quand je l'envoyai en France, je n'en pus pas bien rendre raison. Je the trompai même, en prenant pour la fleur de petits fruits avortéa; mais l'ayant examinée au printemps passé, voici ce que je crois y avoir observé. Quand le bouquet commence à s'épanouir, on volt se? développer une fleur fort petite, mais bien ourerte et bien distincte. Elle a cinq feuilles blanchâtres en forme d'étoile, comme le font communément les fleurs des plantes en parasol ou en ombrelle. Elles sont soutenues par un calice, au centre duquel on voit un pis(i) recourbé en deux petits filaments, et environné de cinq étamines couvertes d'une farine gruméleuse extrêmement blanche. Je rie puis rien dire de l'odeur ayant oublié d'y faire attention; du moin. elle n'arait pas d'odeur forte, puisque je ne m'en suis pas apperçu. Ces etamines sont bientôt desséchées, et cette poussière farineus? s'évopore en peu de temps.

Le pistil de la fleur en s'unissant au calice devient un fruit, prend la figure d'un rein. Il se voûte par son sommet, où le calice de la fleur lui fait une couronne a cinq rayons, an centre de laquelle parait la pointe du pistil ; à ses extrémités il s'arrondit en orillon . et s'applatit par ses côtés, où il se distingue par des lignes épaissen de bas en haut, en manière de cótes de melon ; mais à mesure que ce fruit se remplit, ces lignes s'effacent et paraissent peu sensibles; la peau se rafine, derient plus mince, plus delicate, et courre ure pulpe en chair spongieuse un peu jaunátre, d'où sort un suc vineux et qui est à peu près du goût de la racine et des feuilles. Ce frui? est d'abord d'une couleur vert foncé, il blanchit en approchant de sa maturité ; quand il est mûr, il est d'un beau rouge carmin, et ii noircit en séchant à mesure que la peau se colle sur les noyaux.

Quand le fruit est parfait, il renferme deux de ces noyaux séparés en deux cellules, et posés sur le même plan. Il y a de ces fruits qui n'en ont qu'un et semblent un rein coupé par le milieu. J'en ai trouvé un disposé en forme triangulaire et qui avait trois noyaux. Ces noyaux ont aussi la figure d'un rein, ils sont durs, distinguén en côtes de melon comme le fruit; l'amande en est blanche, et d'un goût un peu amer, ainsi que le reste de la plarite.

Outre ce bouquet on remarque souvent un ou deux de ces fruits portés sur des pédicules séparés et attachés an péclicule commun a deux pouces au-dessous de l'ombelle. Quelquefois il en naít plusieurs qui partent du nœud d'où sortent les branches. J'ai vu une de ces plantes qui me parut plus extraordinaire, elle avait un seconc, 
bouquet bien formé qu'elle portait sur un second pédicule commur, qui s'élevait à côté du premier. (1)

Le Père Jartoux dit que c'est alors un signe qu'on en doit trouves d'autres en suivant le rumb de vent que ces fruits indiquent. Je n'ai point remarqué, au pays où j'étais, que cette observation fut juste. Je crois qu'on n'en peut rien conclure si ce $n^{\prime}$ 'est que ces plantes ont plus de force, qu'elles sont mieux nourries, et que peutêtre elles sont dans un terrain ou dans une situation plus avantageuse à leur accroissement.

On devrait, ce semble, porter le même jugement des tiges qui ont plus ou moins de branches. Il serait naturel de croire qu'elles les produisent ou plus hautes ou en plus grand nombre, à proportion de leur force, et d'ailleurs que leurs racines devraient être plus grossez et mieux nourries, à mesure qu'elles vieillissent. Après tout, ce ne sont point là des règles sur quoi l'on doive compter. On vout des tiges très hautes qui n'ont que deux brancials, i i d'autres qui en ont quatre qui sont fort basses et fort petites. Il se trouve des racines fort vieilles qui sont très-maigres, d'autres au contraire qui n'ont que sept ou huit ans, et qui sont singulières par leur grosseur. La même racine est peut-être plus charnue une année, et plus maigre l'année d'ensuite, du moins est-il certain qu'elles souffrent diverses altérations selon les saisons. Aut printemps elles sont très spongieuses et leur suc n'a point de consistence. J'en ai vu l'expérience dans celles qui ont été cueillies en ce temps-là. Elles ont diminué considérablement, au lieu que celles qu'on cueille en automne sont plus fermes, plus solides, et ne dépérissent pas, comme ayant atteint le point de leur maturité.

Il y a des tiges particulières qui ne portent jamais de bouquet. Alors ce gin-seng ne ressemble pas mal de loin à la salsepareille, qu'on appelie en Canada par corruption chassepareille. Ce n'est point la çarça parilla des Espagnols, qui est une espèce de smilax: mais une autre plante qui jette une tige d'un pied ou d'un pied et demi de haut, terminée par trois ou quatre branches, qui d'ordinaire produisent chacune cinq feuilles, c'est là ce quı de loin la fait ressembler au gin-sengr. Je dis de loin, car à l'examiner de près on y trouvera une différence essentielle et presque totale. Celle-ci jette une racine grêle, également unie, fibrée de distance en distance et tres longue, ce qui lui a fait domner le nom de Tsioterese ou de longue racine. Elle marque son áge par des anneaux entassés les uns sur les autres, et les tiges qui se renouvellent toutes les années,

(1) Toute cette description est d'une exactitude rraiment admirable. Uin de nos amis nous écrit qu'après l'aroir lue attentirement, il a pu reconnaître la prẻsenee du gin-seng dans le bois de St Joseph du Lac des Deux-Mfontagnes. Nous même, arec Mr. le Commandeur Viger, et Mi. Bellemare, nous en arons cueilli plusieurs pieds des plus heaux. et encore chargés de leur fruits près de l'Abord à Ploufe, et tous ceux à qui nous les avons montrés nous ont témoigné à peu près la même surprise que les saurages témoignèrent au P. Lafitau en reconnaissant "leur plante du Canada" - C'est là le gin-seng: mais il $y$ en a partout! Toutefois nous verrons plus loin qu'il y en a peu dans le district de Québec. 
sortent du centre de ces anneaux a fleur de terre, ou elles commencent par un gros bouton. Une seule racine ie cette plante produit jusqu'à trois collets, d'ou s"élèvent autant te tiges. Le fruit ne sort point de la tige qui porte les brancires et les feuilles; mas il s'élève de la racine méme sur un pédicule d'environ cinq ou six ponces, d'où nursent lune, deux, on meme trois ombelles ou bonquets semblabjes à cemx ha lierre. Son fruit est petit, noir, pentagoie couwomé ei renferme de petites semences. Les feuilles s'etendent comme celles du gin-seng, elles ne naissent point du même point central, mas d'espace en espace, le long dies branchers qui n'en ont quelquefois que trois, asser jurent sept, mais plus ordinairement cinq. Les francais en fo... une grande estime, et les sauvages la mettent au rang de leurs vulncraires, mais elle n'est cue de la troisième espèce. Quand j'envoyai le gin-seng en France dans i'esprit de vin, une persomne qui avait en ordre de le chercher, $y$ apporta cette salseparelle: elle ue s'y serait pas méprise si elle avait fait tontes ces observations. II est d'autant plus surprenant qu'elle ne les ait pas faites qu'elle avait le livre en main.

Etant en Canada je n'avais garde de m'imaginer qu'en France on put révoutuer en doute si la plante que j'avais déconverte était le véritable crin-seng. Je ne le comnaissais que par la lettre du Père Jartoux, je n'en avais jugé que par la conformité que je trouvais entre cette plante et la planche qui est gravée dans la lettre du Père Jartoux, et par lexacte descrintion yu il en fait. Je me jersuadais cue la cumparaison qu'on ferait de cette planche et de cette lettre arec la plante entiere que j'enroyais dans l'esprit de vin suffirait pour en convainere d'm seul coup dicil. Cette plante se conserve enroie dans le cabinet de monsietir cle Jussien, docteur en médecine de la Faculté de Paris, qui remplit aujoud'hui avec beancoip d'éclat et de réputation le poste de professeur royal des plantes au jardin (in roi, dans lecpuel il a succété a monsieur Fauron et à monsieur de Tour:uefort, deux des plus habiles fommes que ia France ait eu dans la médecine et dans la botanique.

II me sembie meme quon devrait en être convaincu par la compraraism senle gü on ferait des racines venues du Canada avec celles quon apporte de la Chine. Je les ai en effet examinées et confrontées depuis que je stiis a Paris. Il faut convenir que plusieurs sont si ressemblantes, qu'on ne pourait les discemer si elles étaient confonlue- Cependant celles de la Chine, à parler en général, se distinguent par une conletir un peu plus janne, que les Chinoiaiment, et quoils lti doment par artifiee de la maniere ciont je le dirai ci-apres. Filies ont de plas une centaine transparence, qu'elles acquièrent en vieillissani, les pores de la raciue étant alons plus droits, et les fibres plus pressées et plus unies; l'ean bouillante dans laquelle on les fait macérer peut encore y contribuer.

Cependant j'ai appris yoe monsieur Dauti d'Isiard, docteur en médesine, aiscien professeur royal des plantes au jarlin du roi, avait fait naitre des doites a l'Acalémie Royale des Sciences, ét qu'ils avaient parn très-bien fondés à quelques personues de cet illustre corps.

Toute la diffuculté roulait sur l'autorité qu'on devait donner au 
Père Jartonx. On lui opposait celle de M. Kæmpfer, auteur allemand, qui a impriné en 1712 , un livre intitulé: Amcenitatum Ecolicurum Politico-Phisico-Medicarum....F Fasciculi $\boldsymbol{V}$. \& c. En verlant dh gin-seng il nous dome une iggure de cette plante entieJement dirlérente de celle du Père Jartoux. Ainsi, autorité pour auterite, il paraissait qu'il y avait raisonnablement lieu de couter. Le mérite de celui ciui proposait le doute en pouvait fonder un plus que suffisant.

Monsienr Kompier n'est pas le seul gu'on puisse opposer au Père Jartoux. Monsieur Jean-Philippe Beynius a fait imprimer à Leyde en 1700, une dissertation sur cette racine, et a fait graver une figure de la meme plante, qui n'a nui rapport avec celle de $\mathrm{N}$. Kiæmpfer, di celle clu Père Jartous. Il est vrai qu'il ne fait, ce semble, que ta hasarder, ne sachant quel parti preille, tant les auteurs varient sur ce point. Il en cite plusieurs, et surtout Mentzelius, qui er: tonne sept ou huit figures d'un genre tout différent. Il rapporte ensuite la raison de cette variété, qu'il attribue aux divers noms cilion lui donne. Il est probable que ces différents noms sont les voms de cliverses plantes qu'on aura, mal à propos, confondues avec une seule.

Il est facile à des crens qui se trourent daus un pays étranger de tomber clans cetie forte erreur par rapport à plusieurs choses, mais surtout par rapport a une plante qui est étrangère elle-même au pays ou ils se trouvent. On raisome avec des peuples dont on n'enrend point la langue et doint on n'est point entendu. On comprend une partie des choses qui se disent par gestes et par signes, on wruit comprendre le reste, et de là nait ordinairement une confusion yui divertit ceux qui sont au fair. Jai souvent eu ce plaisir en voyaut les Français jargoner avee nos sauvages, et je suis tombé souvent moi-mêine dans le cas avant que je susse leur langue.

il parait done vraisemblable que tous les auteurs qui nous ont lomé des fiqures différentes de cette plante, ne nous les ont donsees que sur: cies mémoires infidèles, trompés eux-mémes par d'aui.es qui l'avaient été avant eux. Il paraît naturel au contraire de croire que le Père Jartoux qui a vu la plante en Tartarie, endroit cai tout le monde convient qu'on la recineille, et qui s'y est trouvé avec cette armée de Tartares que l'Empereur de la Chine employait a la ramasser, nous cn a donné une figure et une idée plus juste que M. Krinpier et les autres auteurs qui n'y ont jamais eté.

La figure que le Père Jartoux a dessinée lui-méme doit paraitre d'autant noins suspecte, qu'elle se trouve très-parfaitement conborne à la plante découverte en Canada. On peut dire même que celle-ci re l'a été qu'a la faveur de cette fiscure et sur les conjeccures de ce Père. In a raisonné juste en jugreant sur l'idée qu'on lui avait domnée du Canada, que cette plante y devait croítre plutôt u'ailieurs, à cause de la ressemblance de climat et de terroir qu'a cette partie de l'Amérique septeıtrionale avec les forêts de la srande Tartarie.

C'est sur ces raisons que M. de Jussieu et MI. Vaillant m'ont fait Shomneur de me dire qu'ils ne doitaient puint que la plante du Père Jartonx et celle qui vient du Canada ne fussent le véritable 
gin-seng. L'un des deux m'a ajouté qu'il ne croyait pas que désosmais on en pût douter.

Ce qu'on pourrait dire pour justifier M. Kæmpfer, qu'on ne croit pas avoir voulu imposer au public de graieté de cour, c'est qqu'il be peut faire qu'il croisse au Japon une plante dont la racine a quelque rapport au gin-seng, mais dont la tige et les propriétés sont bien: differentes. Il semble l'avoir voulu insinuer lorsqu'il dit qu'il eât défendu au Japon, par une loi expresse, de la vendre pour de véritable gin-seng ou Nisi. Cet auteur s'est trompé en croyant que c'est le vrai gin-seng transplanté au Japon, où il a, dit-il, dégénéré de sa vertu. Les Japonais n'ont du véritable gin-seng que len racines qu'ils achètent des Chinois avec qui ils font commerce.

Ma conjecture sur cela est fondée sur celle de M. Breynius. Cêi auteur ayant observé une différence assez cousidérable entre les racines venues de la Chine et d'autres qui avaient été envoyées du Japon, établit deux espèces de gin-seng ou de Nisi. Il appelle l'ur: Nisi de Corée ou de la Chine, et l'autre Nisi uu Japon : il prononce ensuite sur celui du Japon en ces termes: Je soupçonne que $1 \mathrm{~s}$ plante de la racine Nısi qui croît au Japon, est de tout un autre genre que celui de la Chine, quoique je ne puisse dire quel il est. Cet auteur ajoute que celui du Japon a bien moins de vertu que celui qui vient de la Chine.

Ce qui aura encore pu contribuer à l'erreur de M. Kæmpfer et de quelques autres auteurs, c'est qu'on donne probablement au Japon le nom de Nisi à des plantes de différent grenre, mais dont les racines ont quelque rapport avec la signification du mot. Je suppose ici que le mot Nisi qui est le nom japonais, a la méme signification. que les mots gin-seng et garent-oguen, qui veulent dire la ressemblance de l'homme.

Monsieur Kæmpfer, dit lui-même, qu'on donne dans le Japon le même nom de Nindsin aux panais des jardins et aux panais sauvages, comme on le donne à la plante qu'il croit étre le rrai gur-sens transplanté au Japon.

Guillaume Pison dit la même cliose, c'est peut-être pour cela. qu'il donne sur la foi d'autrui, une figure du gin-seng qui approche de celle des panais. Mais il dit en même temps qu'aucun des Hollandais n'a vu la plante, qui ne -e trouve que dans le Katay et dans la Péninsule de Corée, dans la profoncteur des terres, et à plus de deux cent lieues de la mer.

sįun auteur de bonne foi pourrait tomber dans le méme inconvénient en Canada par rapport à cette plante-là même, si quelqu'un qui ne connut pas le gin-seng, allait le demander à un Iroçuois sous le nom de garent-oguen, que nos sauvages lui donnent, on pourrait lui présenter une autre plante qui a le même nom de garent-oguen, et cont la racine ressemble encore plus parfaitement au corps de l'homme J'y ai distingué communément les bras et les cuissea, ce qui n'est pas si ordinaire aux racines du gin-seng. Cet homme, dis-je, ainsi trompé, se croirait bien autorisé à nous donner cette plante pour le vrai gin-seng, cependant il y a une diftérence entière. Celle-là n'a qu'une seule feuille dentelée, épaisse, longue d'environ. sept on huit pouces, large par sa base à proportion, et terminée en 
pointe; elle n'a point de tige. Les sauvages disent qu'elle ne pousse ni fleur ni fruit; et c'est peut-être la raison pour quoi ils ajoutent au nom de garent-oguen celui de Tsiohontati qui signifie qui n'a qu'ure feuille. Les sauvages mangent la racine de cette plante au printemps, aussi bien que d'autres racines et des pommes de terre, ils s'en servent aussi comme d'un remède topique, pour les genoux et les autres parties du corps, lorsqu'elles sont enflées.

J'ai appris à Paris que M. de Sarrazin, conseiller au conseil supérieur de Québec, médecin et botaniste du roi, correspondant de 1'Académie Royale des Sciencos, qui certainement est très-habile dans son art, dont il parle avec beaucoup de grâce, et qui l'exerce avec beaucoup de capacité et de succès, avait autrefois envoyé du Canada entre plusieurs plantesde ce pays-là, celle que j'ai decouvert pour être le vrai gin-seng, et qu'il l'avait envoyé sous le nom d'Aralia. Il ne pouvait pas alors la comnaître pour ce qu'elle est, la lettre du Père Jartoux n'ayant pas encore paru dans ce temps-là. II en avait aussi envoyé une autre espèce beaucoup plus petite sous le même nom d'Aralia, je l'ai vue dans l'herbier du célèbre M. Vaillant.

Tous les auteurs qui parlent du gin-seng, s'accordent à lui donner de très grandes vertus.

Les Chinois et les Japonais, dit M. Kæmpfer, rapportent diverses propriétés de ces racines. Les principales sont, qu'elles fortifient, qu'elles engraissent, qu'elles sont utiles pour les maux de reins. Il n'est presque point de médecines et il n'est point de cordiaux où ils ne les fassent entrer après les avoir réduites en poudre.

Elle augmente les esprits vitaux, dit le Père Martini, quoi qu'on n'en prenne que la douzième partie d'une once. Quand on augmente la dose elle sert à rétablir les forces perdues, et à fortifier les faibles et les débiles. Elle échauffe agréablement et doucement le corps, lorsqu'on la fait bouillir au bain-marie. Quand elle est cuite elle exhale une odeur aromatique; ceux qui sont d'un tempérament fort et robuste, et qui ont une grande chaleur naturelle, courent risque de perdre la vie s'ils en mangent, parce qu'elle augmente troj) leurs esprits et leur chaleur. II n'en est pas ainsi des malades ou des personnes affaiblies par une longue maladie, elle fait sur eux des espèces de miracles. Les mourants méme trouvent quelquefois du coulagement a en user, par là leurs forces s'augmentent, et ils se trouvent en état de prendre les remèdes qui leur sont nécessaires pour le recouvrement de leur santé. Les Chinois racontent mille autres merveilles de cette racine, aussi la vend-on très cher, et l'on en donne trois fois autant d'argent qu'elle pèse.

Nous pouvons dire avec assurance, ajoute le Père Kirker, que sette herbe est merveilleuse, qu'elle a le pouvoir de rétablir la chaleur naturelle et les forces perdues, c'est ce que l'expérience nous en a appris.

Les plus habıles médecins de !a Chine, écrit le Père Jartoux, ont fait des volumes entiers sur les propriétés du gin-seng. Ils le font entrer dans presque tous les remedes qu'ils vendent aux grands seigaeurs, car il est d'un trop grand pix pour le peuple. Ils prétendent que c'est un remède souverain poir les épuisements causés 
par des travau: excessifs ciu corps ou de i'esprit, qu'il dissout les phlegmes, qu'il guérit la faiblesse lu poumon et la pleurésie, qu'il arrête les romissements, qu'il fortifie l'estomac et ouvre l'appétit, qu'il dissipe les rapeurs, qu'il remédie à la respiration faible et précipitée en fortifiant la poitrine, qu'll augrnente les esprits vitaux et produit de la limphe dans le sang; entin qu'il est bon pour les vertiges et les éb!ouissements, et qu'il prolonge la vie aux vieillards.

En lisant dans la lettre du Père Jartoux tous ces admirables effets, je cloutais presque si ce n’était point la un de ces panacécs universels, et de ces remèdes à tous manx, que l'on vante au delà cle leur mérite. Quoiqu'il assure en aroir fait l'expérience dans une occasion où il était si fatigué et epuisé, qu'il ne pouvait se tenir à che. val, je n'étais pas tout à fait bien convaincu.

J'ai trouvé cependant le Père Jartoux bien moléré, quand j'ai lu lans M. Breynius le détail des proprietés du gin-seng, tel qu'il avait été envoyé du Jap̧on. Ce détail est magnifinue. Il parait outré a la vérité, et MI. Breynius en convient; mais il en rapporte luimême de belles expériences, qui ont rapport à presque toutes les maladies dont il est fait mention dans les relations du Japon. Il assure que ces épreures ont été faites à Leycle, et qu’elles ont été recueillies par M. Frédéric Dekkers, recteur et professeur du collége de médecine de cette ville. Sur ces expérielices on peut juger qu'on ne saurait trop vanter une racine aussi précieuse et aussi sonveraine que l'est celle-ci.

Ce qu’on pourrait peut-étre objecter de plus plausible, en avouant que la plante du Canada est la même que celle de Tartarie, c'est qu'il se pourrait faire qu'elles n'eussent pas les mêmes propriétés : mais sl cette difficulté avait lieu, ce serait intirmer la vertu de toutes les plantes; aussi voyons-nous que les médecins $n^{\prime} y$ ont pas beaucoup d'égard, puisqu'ils employent communément les herbes qui se cueillent dans. le pays où ils se trouvent, quelque autre part du. monde qu'on ait reconnu en premier lieu leur efficacité. Les plantes sont à peu près partout les mêmes. Celle-ci vient naturellernent en Canada comme en Tartarie ; c'est à peu près le même terrain et le l'autre pays, il est done naturel même climat dans l'un et dans de conclure que le gin-seng qui croit en Canada est aussi semblable par sa vertu à celui qui croît en Tartarie, qu'il lui est semblable par la figure; mais les expériences qu'on en a faites, et celles qu'on en fera dans la suite, décideront plus efficacement cette difficuité.

Je demandai d'abord a nos sauvages quel usage ils en faisaient. On en use, me répondirent-ils, pour purger les enfants au berceau. Ils disent qu'elle n'est pas assez forte pour purger des personnes plus âgées ; c'est là sans doute ce qui la fait appeler par quelques-uns la médecine des enfants. Les sauvages s'en servent. aussi pour réveiller l'appétit, quoique le dégoût soit une maladie peu ordinaire parmi eux. Un Huron et un Abenaqui, tous deux habiles a leur manière, me dirent qu'ils l'employaient pour la dissenterie, mais qu'ils le mêlaient avec d'autres plantes. Ces réponses et j'expérience de la sauvagesse dont j'ai déjà parlé, qui s'était guérie trois fois de la fièvre, était tont ce que j'en savais quand j'envoyai le gir:- 
zeng du Canada à Paris, et que le Père le Blanc (1) eut l'honneur de le présenter, Monseigneur, à V.A. R. J'en avais fait l'épreuve sur moi-même, et je m'étais persuadé que par son usage je m'étais guéri d'un reste de rhumatisme dont j'étais très fatiggue, et ciont je ul'ai plus rien ressenti. Je m'en suis servi depuis pour un flux de sang commencé que j'emportai d'une seule prise.

Je n'envoyai que peu de gin-seng à Paris, et je n'en envoyai que pour le faire voir. Je ne laissai pas d'en adresser une petite boíte en province, à une personne incommolée pour laquelle je m'intéressais, elle était malade depuis dix-neuf mois. Le principe de son mal était un dérangement d'estomac qui avait si fort empiré qu'il s'y était joint une fièvre intermittente, avec une insomnie perpétuelle, et un très grand dégoût. Le quinquina dont elle usait ne lui ótait la fièvre que pour peu de jon:rs, il lui cansait méme me grande ardeur dans le gosier et l'échauffait considérablement. Ceux qui m'écrivaient à son sujet m'en parlaient comme d'me personne de qui il n'y avait plus rien à espérer.

Dès qu'elle eut reçu ces racines, elle ell usa durant sept jours de suite. Dès les premiers jours elle recourra l'appétit et le sommeil : mais la fièvre lui augmenta si considérablement sur la fin, qu'elle en serait morte, dit-elle, si elle erit en un troisième accès semblable aux deuxäpremiers qu'elle avait en. Elle crut deroir interrompre l'usage du gin-seng. Son médecin lui fit entendre que cette augmentation de fièvre pourait plutót venir de ce qu'elle avait usé de quelques-unes de ces racines moisies, que de la nature même du remède. Elle en reprit et guérit. Il y a un mois, écrit-eile, que je n'ai plus de fièvre, et de tout mon mal, il ne me reste plus que cle la maigreur.

Je n'ai point fait mystère en Canada de ma découverte. A présent tout le monde y connaît le gin-seng, surtout à Montréal, où tout cet été les sauvages le sont venu vendre au marché, et l'ont même vendu assez chèrement. L'abondance qu'on en a eue a donné lieu à plusieurs expériences.

Monsieur de Louvigny (2), lieutenant du roi de Québec, et l'un des plus sages et des plus braves officiers qu'ait Sa Majesté, en connaît 1'usage et la bonté. Après avoir terminé heureusement et glorieusement, en 1716, la guerre que nous a vions contre une nation de sauvages qu'on nomme les Outagamis ou les Renards, il est remonté à Missilimakinak, en $\mathbf{1 7 1 7}$, pour les obliger à tenir les conditions qu'il les avait forcé d'accepter en leur donnant la paix. Il m'a fait l'honneur de m'écrire de ce pays-là, qu'il y avait trouvé le gin-seng, qu'il l'avait conseillé aux sauvages, chez qui la petite vérole eou-

(1) Le Père le Blanc (Augustin) arrira dans ce pays en 1697; en 1698 il fut envoyé à St. François de Sales, arec le P. Bigot; en 1699 il était Père Spirituel au Collége de Québec ; enfin il repassa en France en 1700 (MS. du R. P. Martin). La Lisle de M. Noiseus fait venir ce Père en 1690, et marque son départ en 1715 .

(2) M. de la Porte Louvigny fut une des nombreuses rictimes qui périrent dans le naufrage du Chumeau, le 25 août 1725 . Il venait d'être nommé Gouverneur des Trois-Rivières. 
rait pour lors, et que ces sauvages s'en sont servis avec succès. C'est en effet un excellent cordial.

Une personne de caractère et de distinction, mais récluite presque toutes les années à l'extrémité par un asthme, résolut de s'en servir. Dès les premières prises elle y reconnut un effet si prompt, qu'elle avouait qu'on lui ôtait, ce semble, le mal avec la main.

Des personnes âgées en ayant fait usage pour des fluxions et des rhumatismes, qui les rendaient comme impotentes, depuis quelques années, en ont été délivrées par une espèce de prodige.

Cette racine est véritablement amie de l'estomac, en remet les levains, dissipe les humeurs froides, pituiteuses et scrophuleuses, subtilise le sang, lui ôte sa grossièreté, et est un spécifique pour y rendre fluide la lymphe. Elle ouvre les conduits des reins et pousse au dehors les sables et les matières glaireuses. Elle excite sensiblement l'appétit, et fortifie véritablement. ILa chaleur qu'elle excite est douce, proportionnée à la chaleur naturelle, et propre à faire une bomme action et par là à remédier à presque tous les maux qui sont produits par les défauts de digestion.

C'est en particulier un excellent fébrifuge : Je connais ciu moins trois ou quatre personnes qui ont été guéries de fière lentes de deux ins, en très peu de jours. Monsieur Breynius dit que quand on en a pris, la fievre diminue de moment en moment. La sauvagesse dont j'ai déjà parlé, m’assura qu'elle avait expérimenté la mêne chose. Cependant quelques persounes en Canada ont éprouvé nn effet contraire, et fait les mêmes plaintes que celle à qui je l'avain envoyé en France. Peut-être que ces différences viennent de la variété des tempéraments, de la disposition où l'on se trouve, ou de la manière de le prendre. Sur quoi les épreuves qu'on en fera dans la suite achèveront de nous instruire. Pour moij'aide la peine à croire que son usage puisse être nuisible, tant sa chaleur me paraît. douce. Il me semble pourtant qu'il est meilieur pour les fievres chroniques et lentes que pour les fievres aiguës. Je ne roudrais paz non plus le donner dans l'acces de la fièvre. Les personnes même d'un tempérament trop vif doivent en user avee précaution; mais on le conseille aux personnes âgées et lanıruissantes. (1)

La manière de prendre le gin-seng, selon $M$ Kampfer, est de le réduire en poudre. La dose est d'ure dragme el demie, infusée apparemment dans quelque liqueur.

On peut s'en servir de cette manière, selon le Père Jartoux. On

(1) On aimera peut être à comparer le passage précédent avee ce que dit ailleurs le $P$. Lafitau.

"Le sin-seng, dont il est probable que Théophraste a voulu parler, et lont les Tartares, qui sont les réritables Scythes, font un si grand usage, a la vertu de soutenir, de fortifier et de rappeler les forces épuiscés. Il a a aussi nn petit gont de réglisse, ainsi que je l'ai dit dans l'écrit que j’ai composé au sujet de celui que j'ai découvert en Canada, et qu'il est facile de s'en assurer bar l'essai de la plante même. Théophraste ne donne point d'autre nom a la plante dont il parle, et a laquelle il attribue une si grande vertu, que celui de Scythica."

(Maurs des Sauvages etc. t. 2 p. 111.) 
coupe la racine par tranches. Il en conseille aux personnes malaCles la cinquieme partis d'une once, et la dixième partie à ceux qui n'en prennent que pour se conserver dans leur embonpoint, encore ne croit-il pas qu'on doive en faire un usage journalier. On met cette dose dans un vai-seau de terre bien bouclié, sur un elemi septier d'eau qu'on laisse bouiliir jusqu’à ce qu'il soit réduit à une bonne tasse. On le prend aussi chaud qu'on peut, et on le mêle avec un peu de sucre pour en corriger le goôt, qui paraît d'abord un peu désagréable. Ce goút consiste dans un sentiment de jus de réglisse. mais qu a un peu plus d'amertume. Quand on y est accoutumé il fait plaisir, et on sent en méme temps une chaleur donce dans la bouche et dans l'estomac qui déclare sa force et sa vertı. On peut rernettre pareille quantité d'eau sur la même dose, et il est bon même la seconde fois. C'est ainsi qu'on en use pour le thé. Je croirais cu'il serait meilleur infusé dans le vin blanc. On en pourrait faire nême une eau comme l'eau de genièvre, qui aurait pour le moins autant d'efficacité, et qui aurait les mêmes usages.

On peut le prendre a jeun, ou mieux encore, après avoir mangé, car il aide la digestion, et guérit mème l'indigestion. Une personne ligne de foi m'a assuré en avoir été cruérie subitement.

Les Chinois ne se servent que de la racine du gin-seng. Le fruit n’est bon à rien. Le Père Jartoux assure que les fenilles prises en gruise de thé, sont aussi bonnes on meilleures que le thé même. Quelques personnes ont tumé de ces feuilles en Canada. Le goût et l'odeur selon leur rapport en sont agréables, et leur fumée abbat les vapeurs.

Personne que je sache n'a encore fait l'analyse du gin-seng. Le frère apotiquaire des Jésuites de Québec, trés hon pharmacien, se propose de travailler l'an prochain à découvrir l'usage qu'on en peut laire par la chimie. J'en ai mis au feu, il n'y brûle point, ce qui me fait juger qu'il a peu de résine; il ne pétille point aussi, ce qui marque qu'il a peu de sels fixes. On peut présumer que sa vertu consiste dans un alcali mêlé de quelques sels volatiles. MI. Breynius rapporte dans la dissertation les expériences quion en a fait et qui ont réussi. Il rapporte aussi les diverses manières dont il a élé cosé et mêlé avee d'autre remédes proportionnés aux maladies pour lesquelles on le donnait. Messieurs de l'Académie Royale des sciences, par les expériences qu'ils seront en état de fire quand is auront une sufisante quantité de ces racines, mieux conditionnées que celles qui viennent de la Chine, poussant plus loin leurs connaissances, nous mettront en état de profiter encore mieux des versus de cette plante. Il faut avoner que nous ne la connaissons pas encore assez bien, parceque nous ne la connaissons que par des sauvages, des Chinois et des Japonais, qui dans le fonds sont de mauvais médecins, peu instruits des principes de l'anatomie et les règles de l'art. C'ependant, il faut a rouer aussi qu'elle ne serait pas si constamment et si universellement estimée à la Chine et au Japon, si elle n'avait en soi de grandes propriétés.

Mais quoiçue des peuples qui composent des royaumestrès vastes, eprouvent tous les jours de bons effets de cette racine, il se pourra bien faire que lorsqu'on la voudra mettre en usage en France, dif- 
férentes persomes $\mathrm{s}^{*} \mathrm{y}$ opposeront comme on a fait autrefois au suje: du tartre émétique et du Quinquina. C'est assez le sort des bons renèdes, mais lè̀s qu'ils sont tels, ils s’accréditent bientôt par euzmêmes et piennent le dessus malgré la prévention.

Pour moi qui ne suis pas médecin et qui ne me pique pas d'écrize comme un docteur en médecine, je ne me suis attaché qu’à rapporter ce que j'ai appris de mes sauvages, à transcrire ce que m'en or: cit les personnes à qui j'ai communiqué cette racine pour en faire usage contre leurs infirmités. C'est le zèle pour le bien public cu: a engagé le Pere Jartoux à nous donner la connaissance de cét. plante, et c'est à lui en effet qu'on en a la première obligation.

Le même zèle m’a encagé dè la cliercher en Canada sur conjecturı ù Père Jartoux. Il a été le pruncipal motil qui m'a obligé cle rendr: un fidèle compte aux savants, aux médecins et air peuple, de tow. ce qui regardait la découverte de cette plante et les utilités qu'or: en doit espérer. Messieurs les médecins, ainsi que j’ai déjà dit, en tireront des conséquences plus justes que je ne pourrais faire, et ils jugeront par le récit que leur feront leurs malades du temps et des précautions qu'il faudra garcier lorsqu'on le voudra employer. L.e gin-seng ne croît point a la Chine, mais en Tartarie. On $1^{9} \mathrm{y}$ rronve entre les 39 et 47 degrés de latitude, boréale, le 10 et le 20 de iongitude, en comptant depuis le méridien de Pékin. Il croît su: le penchant des montagnes, dans d'épaisses foréts, sur le bord des ravines, autour des rochers, au pied des arbres, et au milieu cie toutes sortes d'herbes : mais on ne le trouve point dans les plaines. dans les marécagres ni dans des lieux découverts. Si le feu court lans les foréts, il ne reparaît que trois ans après l"incendie, ce qui prouve, dit le Père Jartoux, qu'il est ennemi cie la chaleur. Auss: ajoute-t-il, il se cache du soleil autail r, $u^{\prime}$ il peut.

Je l'ai fait chercher et je '’a' clierché moi-méme en Canada. II s'en trouve point à Québec, et moins du cóté du nord de la rivière que du côté du sud. On en trouve davantagge en avançant vers le midi, comme à Montréal (1), aux Outaouais, et vers le lac Huron. Ii en croît en grande quantité, dit-on au pays des cinq nations irnquoises : si cela est, les Flamands de la Nouvelle-York en feront bie: leur profit. Quelques-uns qui l'ont vu vendre à Montréal par les sauvages, en auront sans doute envoyé dès cette année en Angleterre.

On n'en recueille pas dans toutes sortes de bois. Je l'ai cherché inutilement dans les foréts touffues et embarrassées de broussailles. Ce n'est proprement que dans les bois de haute futaye, où les arbres. droits et hauts sont engagés par le bas et paraissent naturellemeut allignés comme pour le plaisir de la promenade, qu'on le trouve a: milieu d'une variété admirable d'herbes médicinales, qui naissent au pied des arbres, entre les racines et les pierres, d'où il est trè. difficile de l'arracher.

Un sauvage me dit que le gin-seng ne croissait que dans cie

(1) "Gin-seng has nerer been found far north of Montreal," dit Kalua, qui se trourait en Canada, dans le temps même où l'on cueillait le gi:seng arec le plus d'empressement. 
mauvaises terres: mais il se trompe, car quand ces bois francs sont abbattus on peut dire que ce sont les meilleures terres du Canada. La terre en est noire, le grain un pen sabloneux, et le blé y vient à plaisir.

Le gin-seng aime lombre, aussi bien que les plantes dont ces bois sont remplis. Quand les terres sont nouvellement défrichées il $y$ en reparait encore quelques racines qu'on n'avait pas arrachées en défrichant, mais ii ne s'y en reproduit jamais d'autres. Je ne le rrois pas pour cela ennemi de la chaleur, car cette racine est chaude. D’ailleurs en été, il fait une chaleur encore plus forte et plus étouffante dans ces bois qu'en plein air. J'aimerais mieux dire que ces plantes à qui l'ombre est si favorable, étant trop agitées par l'action imniédiate du soleil et d'm air trop ouvert, y sont renfermées dans ia terre comme dams un sein stérile, tandis que d'autres à qui ce grand air et l'action immédiate du soleil sont plus propices, se développent et croissent à plaisir ; ce qu'elles ne pourraient faire à l'abri des forêts. J'ai vu moi-même cette expéricnce dans le cours d'une année; ayant fait abbatre durant l'hiver un ou deux arpents de bois, le printemps suivant au lieu de ces herbes amères qui y étaient il n'y vint que du chiendent, du treffle, du cu: : s's, et d'autres herbes semblabies qui ne croissent qu'en plein cha...p.

ie doutais, Monseigneur, si ces racines transplantées en Fiance, réussiraient et conserveraient lenr vertu. J'en ai apporté pour qu'on jut s'en assurer. le les ai levéss en mottes, el sans qu'elles aient été séparées de leui propre terre et j'ai eu l'honneur de les présenter a V. A. P. Monsieur de Jussien à qui Elle a fait la grâce de lui en domner une partie. Ies a visitées. II les a trouvées bien fraîches et ell bon état; il we doute pas quielles na fassent merveilles cette année au jardin royal, ou il les a portées par l'ordre de V. A. R. (1)

Je crains que les graines ne réussissent pas si bien. Comme on a eu beau semer la graine, dit le Père Jartoux, sans que jamais on l'ait vu pousser, il est probable que c'est ce qui a domné lieu a la fable qui a cours parmi les Tartares. Ils disent qu'un oiseau la mange dès qu'elle est tombée à terre, et que ne pouvant la digérer, il la purifie dains soll estomac. et qu'elle pousse ensuite ou il la laisse tomber avec la fiente.

Ce qu'il y a de certain c'est que cette plante vient avec peine. J'en ai trouvé qui avaient près de cent ans. Ces racines prociuisent une tige qui tombe et se renouvelle toutes les années. Les plus belles tiges portent jusqu'à 34 fruits, dont la plupart sont doubles, si l'on supputait tous les germes suivant les années de la racine, le nombre des nouvelles plantes qui doivent se former à côté, et le nombre des germes et des amnées de celles-ci. le tout irait à l'infini.

Cependant il ne s"y trouve jamais plus de sept ou huit racines dans les divers cantons où elles naissent les unes auprès des autres.

(1) On yous assure qu'au séminaire de Nicolet on avait transplanté, avco beaucoup de soin, un pied de gin-seng (le seul qu'on eût pu trourer. dans les bois environnants) ; il arait poussé des feuilles et des fleurs et paraissait rigoureux, quand il commença ì se faner, et bientôt il fut complètement desséché. 
ainsi la plante sera bientôt détruite auprès des habitations françaises. et il faudra l'aller chercher an loin dans les hois. ce qui la rendra rare et d'un très-grand prix.

Le temps de la cueillir est celui de la maturité, c'est-i-dire depuis le mois de septembre jusqu'anx neiges. Ceux qui venlent en taire sècher la fenilie doivent la prendre sur la fin d'aoút, avant qu'elle jaunis:e. La racine devient a rien quand on in cueille avant 'e temps-lit, ainsi que je l'ai déja dit. Quand on l'a arrachée de terre il faut la laver soigneusement, coliper Ja racine par rouelles en long pour qu'elle sèche plus aisément. Il vant mieux la faire sècher à l'omire qu'au soleil et an feu, et la conserver en lieu sec.

La racine vant mienx étant sèche, que lorsqu'on la tire de la terre, alors elle est implégnée d'une humeur qui lui ôte de sa bonté. et qui s"évapore à mesure qu'elle se desscehe. On y troure en effet une difiérence considérable an cout, qui est bien plus fort quand elle est sèche que quand elle est nourelle. D'ailleurs elle ne fait point vomir étant nouvelle, ainsi que l'écrit M. Preynins sur le rapport qui lni en a été fait.

Cette plante est trés délicate et se gate nisément. Ville moisit d'abord cians un lieu humide, et les rers s'y metlent quand elle vieillit. Celles qu'on apporte de la Chine en passant denx fois la ligne doivent fermenter considerablement, et par conséquent perdre beeueoup ite leurs sels volatils, en quoi consiste lenr vertu. De la vient qu'ordinairement elles sont tontes rermoulnes. Celles qui viendront du Canada seront incomparablement meilleures, puisqu'elles sernnt plus fraíches et mieux conditionnées.

Le Père Jartonx dit que ceux qui cueillent le gin-seng n'cu conservent que la racine, qu'ils enterrent dans un méme endroit. ce qu'ils peurent en amasser durant dix ou quinze jours, qu'ils ont soin de la bien laver et de la nettoyer avec des brosses pour en oter toute la matière étrangère; qu'ils la trompent ensuite un instant dans de l'eau presque bouillante, et qu'ils la fort sècher a la fumée d'un millet jaune, qui lui communique un peu de sa couleur. Le millet renfermé dans un vase avec un peu d'em se cuit à un petit feu. Les racines conchées sur de petites trarerses de hois an-dessus du vase, se sèchent peu à pell sons un linge, nu sous un autre vase qui les couvre.

M. Kanfer rapporte la chose un peu différemment. Quand les racines sont fraîchement arrachées, dit-i! ; ou les fait macérer trois jours dans de l'eau donce, ou ce qui est mieux encore, dans la seconde ean ou l'on a fait cuire une espèce de ris ou de millet, et on les y met tremper quand cette eau est froide. Ainsi macérées dans un vaisseau d'airain et couvert, or les suspend a la rapeur de cette eau sur le feu. Alors étant desséchées depuis le bas jusques vers le milieu, ces racines acquièrent une couleur rousse, résineuse et presque transparente. C'est la marque de leur bonté. Comme je ne crois point que cette couleur et cetie transparence ajontent rien a leur vertu, je crois cette préparation peu nécessaire. Si on souhaitait néanmoins qu'elle le fut pour la conservation du gin-seng, et qu'on vonlut le porter à la Chine pour le trafiquer, on pourrait y 
faire la mème préparation en Cauada avec les mais ou blé-d'inde . dont usent nos sauvages.

Quand j'eus découvert le gin-seng, il me vint en pensée que ce pouvait ètre une espèce de mandragore. J'eus le plaisir de voir que je m'étais rencontré sur cela avec le Père Martini, qui, dans Fendroit que j’ai cité, et qui est rapporté par le Père Kirker, parle en ces termes: Je ne saurais mieux représenter cette racine, qu'en disant qu'elle est presque semblable a notre mandragore, hormis que celle-li est un peu plus petite, quoiqu'elle soit cie quelqu'une de ses especes. Pour hoi, ajonte-t-i\}, je ne doute point du tout qu'elle n'ait les mémes qualités et une paraille vertu puisqu'elle lui ressemble si fort, et qu'elles ont toutes deux la même figure.

Si le Perc Martini a eu raison de l'appeler une espece de mandragore a canse de sa figure, il it en tort de l'appeler ainsi à cause de ses propriétés. Nos especes de mandragore sont uarcotiques, rafraichissintes et stupéfiantes. Ces qualites ne conviement point du tont au grin-seng. Cependant!idée du Pèse Martini, que j’ai rue justifiée ailleurs, ma donné envie de poussel plus loin na recherche. En eifet, ayant trouvé que notre mandrargore d'aujourd'hui, d'un commun sentiment, n'était pas ia mandragore des anciens, j'ai eru qu'en cherchant un peu, ei qu'en comparaut le gin-seng avec ce que les anciens ont dit de leur mandragore, on pourrait soutenir que e'est l'anthropoinurphos (1) de Pythagore, et la mandragore de Théophraste. C'e que j'eri dis pourtant est moins pour donner nes conjectures pour des certitudes, inte jour les soumettre anx savants et leur donner lieu de pousser plus lom leurs recherches.

Voici lonc comme je raisonne. Théuphraste est le premier des anteurs anciens qui aient écrit des plantes. Théophraste nous fait ia description d'une mandragore, qui ne nois est point connue; il est évicient aussi qu'il ne connaissait point celles que nous connaissous aujourd'hui, di moins sous ce nom-là, de là on pourrait conclure que celle de Théophraste s'est perdue tt qu'on lui en a substitué une autre.

Il est facile d'expliquer comment la mandragore des anciens a pu s'être perdue. Premièrement. Elle aura été sans doute d'une grandt' recherche dans les premiers temps, à cause de ses effets singuliers. dont on peut voir des exemples dans l'antiquité. Secondement. La difficulté que cette plante avait à se multiplier l'aura rendue rare, et il est probable qu'elle ne se trouvait que dans les foréts. Le pays s'étant dans la suite décourert et les racines en ayant été arrachées avant la maturité cle leurs fruits, la plante aura été en peu de temps épuisée. On peut conjecturer arant l'évènement, qu'il en sera ainsi du gin-seng. Cette raciné étant fort précieuse, produisant peu, et ne croissant qu'à l'ombre des forêts.

La mandragore des anciens étant ainsi perdue, ou lui en aura substitué une antre à raison de quelque rapport commun à l'une et à P'itutre. Dos mandragores ont des racines qui ont quelque ressem. hance arec le corps de l homme depuis la ceinture en bas, leurs semences som blanches et ont la figure d'un petit rein, c'est sans

(1) De forme humaine. 
doute ce qu'elles ont de commun avec la mandragore et cela se trouve parfnitement dans le gin-seng; le fruit du gin-seng a de surplus la même figure que les semences: il reste maintenant à voir ce que la mandagore de Théophraste a de particulier, et a examiner s'il convient au gin-seng, pour cela recueillons tout ce qu'en dit Théophraste.

En premier lieu, Théophraste recomat une tige a la mandragore, et établit une ressemblance par la tige entre elle et la féruie. Voici ce qu"il dit an chapitre second du livre six: "Entre les autres " (plantes) i! y en a quelques-unes qui approchent plus de celle-ci " (la férule) par leur lige, telles sont li mandragore, la eigüe l'el"lebore, ete."

Cette ressemblance doit être yrise de celle quiil établit lui-méme ailleurs, entre ies plantes qu'il rance en diverses classes, selon la diversité de leurs tiges, e'est au chapitre 8 cin livre 7 qu'il parle ainsi: "Futre tnutes les plantes. il y a une diflérence établie ét re* connue de tmit le monde, elle se prend de la varióté des tiges, " car il y a des tiges droites, des tiges nervenses. des tiges qui tom" bent et ne durent qu'une année, ides iges qui l'accrochert, des $\because$ tiges qui rampent a terre, il $y$ en a qui n'ont qu'une seule tige, " quelques-unes en ont beancoup. et quelques autres peu." Ce que je mets ici en précis, est étendu plus au long clans tont ce chapitre 8 du livre septième.

Cente iliférence générique étant nimsi établie, chemehons en quoi eousiste la ressemblance particulière entre la férnle et la mandragore. C"est ce qu'on peut voir dans la description de la férule, au même chanitre du livre sis. il lui donne ces denx qualités: " Flle ne pio"duit qu'une seule tigro, et celte tige tombe et renaît tontes les "années :" or, ce ques "wophraste dit de la mandragore et de la férule, se tronve rnai du gin-ang, qui na ponsse qu'mo seule tige, que la méme année voit se former cí se détruire, et ne peut absoiument convenir aux deux especes dusolanum furiosum ou lethale qui produisent dix ou douze tiges sur un senil pied, ansi l'opinion de presque tous jes botanistes, qui croyent que ces esueces de solanum. et en particulier celui a qui lo Italiens ont dosmé le nom de Belladona, sont ia mandragore de Theonhraste, se tronve ici renversée par Théophraste méme.

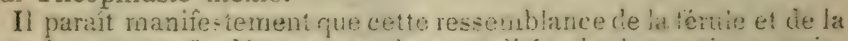
mandrague e-t fon ée sur ces denx qualité de leurs tiges, puisyu'immédiatement apres avoir fat cette entnparaison il etabiit une. nouvelle ressemblance par les tiges cutre antres plantes, et comme une nouvelie elarse. "Queiques-n!es ont dit-il, des iiges nerveuses. "Tels sont le fenouil, etc."”

Eir recond ifen, Theophäiste susprime ansi an nence ehapitre second du sixieme livie. "Le fruit de la mandragore a cela de " particulier, qu"if e-t noir, qu'il neít en grapje, eic... (jüil at un goût " vineux." Examinon: ces trois qualités.

A la vérité le frut du gin-sengr est d'un très beau ruigge dans sa maturité, mais en séchant sur pied il devient si noir qu'at peine apperçoit-on en quelques-uns qu'il ait été ronge. Il en est de mêne de quelques autres plantes $t-t$ en particulier de l'Apalachine, qui 
nous est venue réecmment de la Louisiane, on peut dire que son truit est noir quoiqu'on assure qu'il y a un temps où il est rouge. Communément le fruit de ces sortes de plantes is successivement difíerentes couleurs. Ceux qui ont commenté Théophraste et qui ont prétendu avoir trouvé sa mandragore ont expliqué difiéremment le mot grec ragodès. Quelques-uns l'expliquent d'une grappe et d'autres d'un grain, de quelque matière qu'on l'entende, si l'on considere le fruit du gin-seng ou l:ombelle qui porte les fruits, cela Iui convient parfaiternent ot aussi bien qu'aux fruits des deux espèces de solinum, dont l'un, tel que la morelie, produit une ombelle. ou grappe sembiable à celle du lierre, et l'autre ne produit qu'un grain qu on appelle faba inversa.

La troisième qualité, qui est d'avoir un foút vineux, est propıe à p'usieurs plantes qui portent des bayes; le gin-seng en est une. l'eau qui se répand dans la bouche, quand on presse le fruit du ginseng, tient du goût de ses racines et de ses feuilles.

En troisieme lieu, Theophraste au chapitre nenvieme du neuvième livre, décrit les superstitions des anciens en cueiliant la mandragore: les sauvages qui ne sont pas encore chrétiens, haranguent aussi leurs herbes médicinales et pratiquent autant de vaines cérémonies que faisaient autrefois los payens. Comme je n ai lu Théophraste que depuis mon arrivée a Paris, je ne puis savoir si les sauvages employent les mêmes superstitions que Théophraste rapporte, il serait asse\% singulier que ce fussent absolument les mêmes. mais quand bien méme elles seraient différentes, ce ne serait pas un préjugé contre le gin-seng, depuis un si long intervalle de temps, i! s'est pu faire bien des changements qui ne tirent point à conséquence.

En quatrième lien, Théophraste décrit les propriétés de sa mandrağore, au chapitre dixieme du méme livre neuvième - " La fenille - de ia mandragore, dit-il, pétrie avec de la farine est bonne à ce * qu'on assure pour les ulcères, sa racine raclée et macérée dans le . vinaigre sert poill l'érésipele, pour toutes les fluxions de goute, * pour concilier le sommeil. etc. On la donne dans le vinaigre ou "dans le vin."

Théophraste dit ensuite que la maniere de la conserver est de lit cuuper par tranches, qu'on enfile el qu'on suspend à la funée. Ces effets de la mandragore de Théphraste se rapportent mieux à ceux qu'on atılibue au cin-seug qu'à ceux des deux espéces de solanum, (lont j’ai déjà parié, qui sont de réritables poisons qui feraient mourir si on ne les dosait avec beaticoup de précaution.

(Quand Théophraste dit que la mandragore est bonue pour faire cormir, il ne dit rien qui ne soit conforme aux expériences qu'on a fait du gin-seng, mais le gin-seng ne produit pas cet effet par une qualité narcotique, froide et stupéfiante, qui serait dangereuse, mais par accident, er ôtant les causes de l'insomnie.

Je n'ai point lu dans Théophraste que la mandragore tit mourir, si (n) en prenait avec exces. J'ai cependant cherché avec eractitude ront ce qu'en dit cet ancien auteur, et je l'ai rapporté fidèlement. Il est vaii que le Père Martini dit du gin-seng, que si les persomes lobustes et vigoureuses en mangent, elles courent risque de perdre 
ia vie, parce qu'elle augmente trop leursesprils vitaux et leur chaleur naturelle. Je crois pour moi qu'il en faudrait pour cela un loug et indiscret usarge, tel qu on en pourait faire des meilleures choses. qui ne conviement pas également à tous les tempéraments.

La seconde espèce de garent-oguen tsiohontati dont j'ai déja parlé, et qui selon le rapjort des sanvages ne produit qu'une seule tenille sans tige, sans fleur et sans fruit, est mne autre espèce de mandragore, je ne sache pas que personne en ait encore parlé : elle plent faire une troisième espèce avec les deux mandragores de Dioscoride qu'il nomme akaulos.

Les sauvages se servent d'une autre plaite pour rétablir les force. perdues, ils la nomment 'T'sioterese-góa, ou la grunde longue racine. pour la distinguer de la salsepareille. qu'ils nomment simplement T'sioterese ou la longue racine. Les Français la connaissent sous le nom d'anis sauvage. Les sanvages sont les plus grands mangeurs dn monde, mais ils savent aussi parfaitement supporter la faim ; quand leurs provisions leur manquent ils se ceignent fortement le ventre, et fatiguent doublement à courir pour chercher de quoi vivre et a souffir leur disette, alors quand leurs genoux chancellent et que leurs yeux commencent a cloubler les objets, ils prennent une poigrnée de la poudre de cette racine qu'ils délayent dans de l'eau qu'ils boivent, et leurs forces sont sur le champ rétablies.

Ils font le méme reméde avec succés et avec la même préparalion pour se cruérir du coup de soleil, cette racine est d'ailleurs un des plus excellents vulnéraires qu'on puisse trouver ; j'en ai apporté un peu, et il n'est personne qui ne juge de sa vertu par son goút aromatique. Je l'ai vu dans l'herbier de M. de Jussieu et dans celui de M. Vaillant.

Il ne me reste plus qua a sonhaiter que les expériences qu'on fera en France du gin-seng, vetu du Canada, puissent répondre à celles qu'on a déjà faites en ce pay: là et se trouvent telles qu'on parait ies promettre. 1]. de Jussien ma fait l'homneur de me dire qu'il S'en était déjà servi arec sncèes, et qu'il avait arrêté un vomissement qui n'avait pu céder au remèdes ordinaires. Mais le comble de mes souhaits serait que l"usage de cette plante servit, Monseigueur, à prolonger jusqu'à une extrême vieillesse, des jours aussi nécessaires et aussi précieux que cenx de V.A.R.

Ces voux ardents que je forme pour la conservation de V.A. R. par reconnaissance pour les obligations qui me sont particulières, et par la gratitude qui mo est 'ommune avec la compagruie dont j'ai l'honneur d'étre, rogardent *.core le public qui est intéressé a la vie d'un prince, dont les proje : tendent tous à la félicité des peuples, d'un prince dont les premir : soins ont été d'envoyer des ordres jusques aux extrémités de lis wre, pour attirer de par tout dans le cour de la France, tout ce qui peut contribuer à la rendre florissante, d'un prince qui n'a approuvé les soins que je me suis clonné pour découvrir cette plante, et n'a paru content dè ma découverie qu'autant qu'il a été flatté que puisqu'elle est d'une très graude utilité pour la cuérison de plusieurs maladies che\% des nations très: reculées, elle peut aussi devenir utile à un peuple qui l'aime, et dont par recomnaissance, il cloit être les délices. 
Ce n'est pas asse\%, Monseigneur, que le public fasse des surux pour la conservation de V. A. R., tous les arts qu'elle honore si particulièrement de sa protection, doivent travailler à immortaliser son nom et sa gloire. Ce n'est pus seulement l'histoire ou la poésie, le pinceau on le burin qui transmettent les sourenirs des grands homines à la postérité, de tous temps, les botanistes ont prétendu avoir ce droit et ont célébré la mémoire des princes qui ont favorisé cette science en leur consacrant de nouvelles plantes. Ces plantes portent encore leurs noms, ils ont passé jusqu'it nous et nous les conservons avec respect. En conséquence de cette possession oin sont les botanistes. puisque $\mathrm{V}$. A. R. a eu la bonté de me permettre de lui présenter ce mémoire et de lui ofrir cette plante, je me flatte qu'Elle ne désaprouvera pas que je prenne encore la liberté de lni domer le nom de Votre Altesse Rovale, et de la nommer duielianu Canadensis, Sinensibus-Gin-seng, Iroqxis Garent-oguen(1). On lit verra fleurir celte amnée pour la première fois en France, et il n'est personne qui ne la voye croitre volontiers et qui ne se fasse un plaisir de la connaître sous un nom si auguste.

Quoique j'aie découvert cette plante en Canada, et que par celte raison je puisse la regarder comme un bien qui m'appartient, ce -':ait cependant aux maîtres de l'art qu'il conviendrait de donner c'e nom avec autorité plutôt qu'à moi, mais ce que $V . A$. R. a fail depuis peu avec une magnificence royale en faveur de la hotanique. envoyant des personnes intelligentes dans les Indes, dans l'Ainérique ét dans lés royaumes voisins, pour y faire de nouvelles découvertes, les intéresse à approuver ma hardiesse, et à conserver m nom qui est pour eux une marque de la protection dont $V$. A. R. Jes nonore, et qui en est me pour moi du pinfond respert aver lequel je stivis,

Monseigneur,

De Votre Altesse Royale.

Le très humble, très obéissant.

Et très soumis serviteur,

JOSEPH-FRANCYOIS LAFITAU,

De la Compagnie de Jésus,

Missionnaire des Iroquois din Sault St. Louis dans la Nlle. Franee.

(1) Les botanistes aujourd'hui ne désignent le gin-seng que gous le nom de panax-quinque-foliun. 



\section{$\mathbb{N O T}$}

Nous nous sommes procurés des documents qu nous permette. d'ajouter quelques nouveaux détails à ce que nous arons dit du Père Lafitau et du gin-seng. On voudra bien nous permettre de les citer ici tels que nous les avons, sans aucune transition :

Une lettre que le marquis de Beauharnais (1) éclirait le 13 octobre i727, au ministre de la marine, le comte de Mraureyas, nous parle de certains mémoires, que le Père Lafitau aurait composés sur une question politique des plus importantes et des plus délicates. "J'ai l'honneur, dit M. de Beauharnais, de rous envoyer ci-joint, un mémoire que m'a donné ie rérére:d Père Lafitan, au sujet des différends entre les denx couronnes, sur les prétentions des uns et des antres. Comme ce mémoire peut servir, MIgr., à celui auquel il me dit aroir travaillé arec M. Begon, j'ai cru devoir rous l'envoyer."

Ces écrits sont probablement encore conservés aux archives du gouvernement français; leur publication ne jourrait qu'ajouter à la gloire du sarant Père, car nous ne doutons ras qu'il n'ait traité cette question desfrontieres arec toute la supériorité dont il a fait preure dans ses autres ourrages, et il nous semble qu il serait assez c rrieux de rapprocher sez preures et ses arguments de ceux des hommes détat et du diplomates de cette époque.

On nous a obligeamment communiqué le passa ge suivant de Kalm, dont l'ourrage est très rare. Ce sarant Suédois, se trourait en Canada en 1749 , au moment où le commerce du gin-seng était en grande actirité. Voici ce qu'il dit :

"During my stay in Canada, all the merchants at Quebec and Montreal, receired orders from their correspondents in France, to send orer a quantity of gin-seng, there being an uncommon demand for it in this summer. The roots were accordingly coilected in Canada with all possible diligence; the Indians especialls trarelled about the country, in order to collect as much as they could together, and to sell it to the merchants at Montreal. The Indians in the neighbourhood of this Town were likewise so much taken up with this business, that the French farmers were not able, during that time, to hire a single Indian, as they commonly do to help them in the harrest. Many people feared lest by coutinuing, for sereral successire Jears, to collect these plants without leaving one or two in each place, to propagate their species, there would soon be rery few of them left, which I think is very likely to happen, for by all accounts they formerly grew in abundance round Montreal; but, at present, there is not a single plant of it to be found, so effectually have they been rooted out. This obliged the Indians, this summer, to go far within the English boundaries, to collect these roots. After the Indians have sold the fresh roots to the merchants, the latter must take a great deal of pains with them. They are spread on the floor to dr5, which commonly requires two months and uywards, according as the season is wet or dry. During that time, they must be turned over once or twice every day, lest they should putrify or moulder. The superior of the clergy here and several other people, assured me that the Chinese value the Canada gin-seng as much as the Tartarian, and that no one has ever been entirely acquainted with the Chinese method of preparing it." ...................................................

(1) Charles de Beauharnais fut gouverneur du Canada de 1726 a 1747. Sa famille, originaire de la Bretagne, a produit Alexandre, vicomte de Beauharnais, qui épouse Joséphine, depuis imperatrice. 
Voici ce que Marr. Verroles, vicaire aspostulique de la Mantchourie, disant du gin-seng en 1813.-(Ann. de Prop. de la Foi, Nó. XVI, pages 142, 143.)

"Il en est de mème pour le Jensen, cette plante fameuse, ce foxique si excellent, le premier sans contredit de l'univers. Lorsque les forces ritales uanquent, totalement épuisées, et que le moriboud ra trépasseı", donnez-lui le poids de quelques grains de Jensen, il revient à la vie; continuez chaque jour et sa vigneur renaît aussitôt, et vous pouvez le soutenir encore plusieurs mois. Le prix dn Jenseu est eshorbitant, c'est presque incroyable, près de cinquante mille francs la livre!"

Ii faut arouer que s'il n'y a pas là une erreur de chitfre, un pareil prix est raiment tabuleux. La seule montagne de Montréal pourrait fournir du gin-seng pour des millions.

Ce qui suit semble moins extraordinaire.

"Le bon, l'excellent Jensen, disent les Chinois, estt le plus rieux; il doit être sauvage : aussi celui de Corée qui vient par la culture, est-il extrêmement inférieur en qualité. A la foire annuelle de Corée, on le vend en fraude, au su des mandarins qui ferwent les yeux. Bien que fort élevé, le prix du Jensen coréen est pourtant raisonnable: environ deux cents francs la livre. Je vais tâcher de m'en procurer de la graine, et en ce cas, l'Europe pourra posséder cette planie admirable.

"Elle ne croît point dans le nord de la Mantchourie, sans doute à cause de sa température glacée."

Dans la lirraison précédente il s'était gli_sé quelques erreurs que nous tenons à corriger.

Le mot Kanahwalie ne signifie pas rapides; mais Au rupide. Le vénérable M. Dufresne du séminaire de St. Sulpice, nous apprend que ce mot se compose de onuú, rapile, et de lié particule qui indique la localité, uu : l'usage permettant de changer $o$ initial en ka, on a enfin Kunuwake. (Pron: Kanawaké l'iroquois, n'ayant pas d'e muet.)

Diapres ce Monsieur, le mot Tsiohontali (page 27) peut se trourer chez quelques reuplades iroquoise.s arec cotte signification; mais il ne semble pas formé régulièrement : les règles de la grammaire demandent Tsiohonlut : ati placé à la tin de certains substantifs, auxquels il est joint, signifie ordinairement d'un côté, lorsque ces substautifs sont précédés dé ska ou de tsi, qui alors deviennent les initiales de ces substantit's, et ne forment qu'un seul mot arec eux, de sorte qu'on ne pourrait pas les retrancher, sans changer le sens-ainsi par exemple-Ohonte, vert, tsiohontat une plante verte; Tsiohontati, d'un côlé de la plunte, etc.

De même pour Tsiolerese, (pages 23, 38): Otera, racine; Tsioterat, une racine: silion veut exprimer une longue racine, il faut retrancher les deux dernieres lettres de Tsioterat, et mettre a la place $e s$, pour le singulier, et cshons pour le pluriel, qui expriment la !ongueur: ainsi on dira T'sioteres, ou suivant lusage de plnsieurs, Tsioterese q i signifie une longue rucine. Le mot tsi n'a pas par lui même la signification de l'unité, il ne l'a que quand il est linitiale de certains substantifs dans lesquels l'usage permet de l'employer; (hors de la il anrait une signification toute différente), et dan ce cas le substantif dont il est l'mitiale doit se terminer nar at ou $t$, suivant que lusage le lemande, à moins que ls subtantif ne soit joint à un aljectif, qui ne permettrait pas cette terminaison, comme on le voit dans les exemples précédents.

Page 15, note, lère ligne après fut, lisez nommé.

Page 19 , note, lère ligne lisez Dufresne. 


\section{T $\triangle$ B L E .}

Le Pere Lafitau et le Gin-Seng,$\ldots \ldots \ldots \ldots \ldots \ldots \ldots \ldots \ldots \ldots \ldots \ldots \ldots$ Agriculture négligée pour le gin-seng, $\ldots \ldots \ldots \ldots \ldots \ldots \ldots \ldots \ldots$. 41

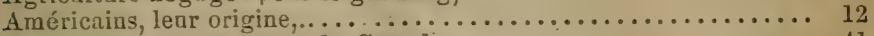
Beauhırnais, gourverneur du Canada, $\ldots \ldots \ldots \ldots \ldots \ldots \ldots \ldots \ldots, 41$ Garnier (le P. Julien),............................ 12 Gin-ssag-Son prix en Chine, 5,6 ; en Mautchourie, 42 ; à Québec, 6, 7. - Il est déprécié et pourquoi, 6, 8.-Il existe encore, 6, 23 (note). - Le commerce s'en fait encore, 6 .

Lafitau (le P. J. F.) - Sa naissance, son arrivée en Canada, 4.-Il découvre le gin-seng, 5.-Il retourne en France, 9; va à Rome, 12.

- Ses écrits, 9, 11, 12, 13, 41.-Sa mort, 13.-Son portrait, 14 .

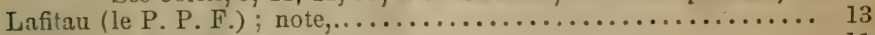

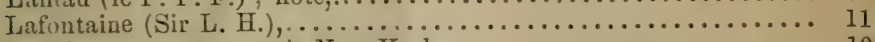

Lovelace, gourerneur de New-York, ................... 10

Marcoux (J.) Prêtre Missionnaire, ........................ 13

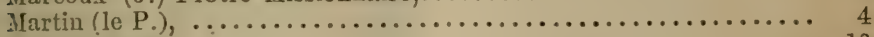

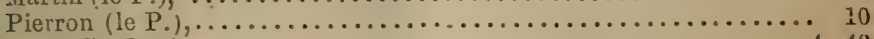

Sault St. Louis, ............................... 4, 42

Traite de l'eau-de-vie, .............................. 9

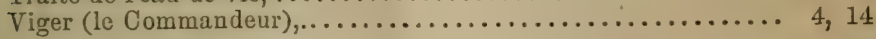

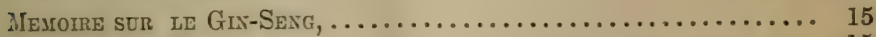

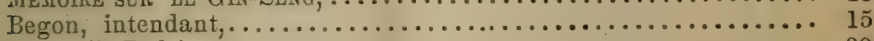

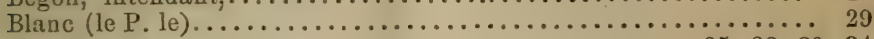

Breynius,............................... 25, 28, 30, 34

Danti d'Isnard,................................ 24

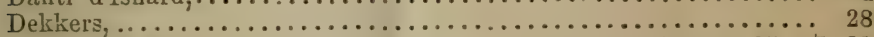

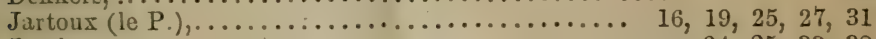

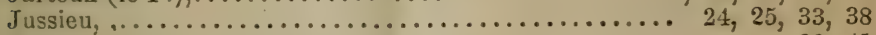

Kalm, .................................... 32,41

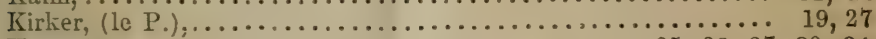

Krempfer, ........................... 25, 26, 27, 30, 34

Louvigny $, \ldots \ldots \ldots \ldots \ldots \ldots \ldots \ldots \ldots \ldots \ldots \ldots \ldots \ldots \ldots \ldots \ldots \ldots, 29$

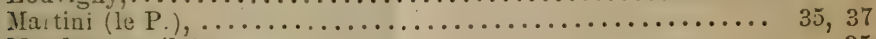

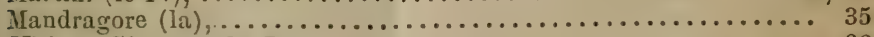

Nisi, ou Gin-seng du Japon, ................................ ${ }_{26} 6$

Notes, . ...................................... 41

Gin-seng-Les PP. JJ le font connaître en Europe,........... 16

- Le P. Jartonx le décrit, ..................... 16

-Le P. Lafitan le déconvre en Canada,......... 18, 22

-Nom du Gin-seng en Irognois, ................. 19

- $\quad$ - en Tartare, en Hantchoux (note), .... 19

-Nom que lui donne le P. Lafitau,................. 39

-Description de la plante,.................... 19, 33, 36

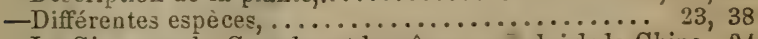

- Le Gin-seng du Canada est le même que celui de la Chine 24

- Ses propriétés,............................. 27

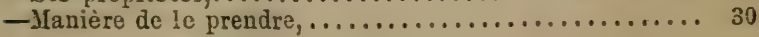


-Analyse de cette plante, .................... 31

-Dans quels endroits elle se troure, $\ldots \ldots \ldots \ldots \ldots \ldots \ldots,{ }_{32}$

-Temis de la cueillir, ........................ 34

- Mauière de la préparer,.................. 34, 42

- Sa ressemblance avec la Salsepareille, ............. 23

Pison, Guillaume, - - M Maudragore, .............. 35

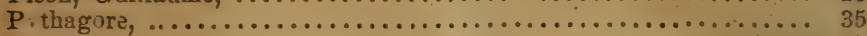

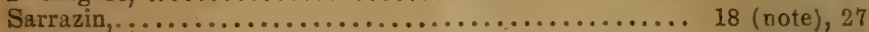

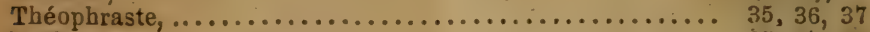

Vaillant,................................ 25, 27, 38

Verroles, Mgr.,..............................

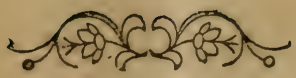






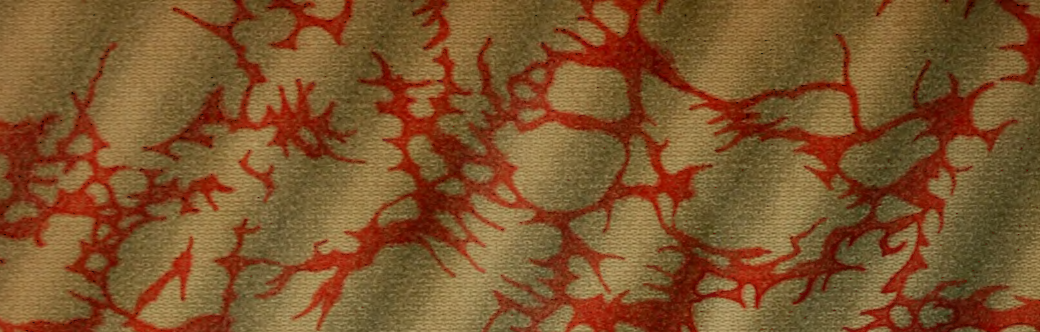

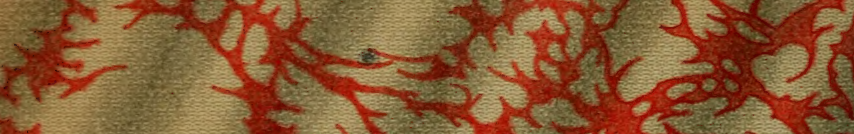

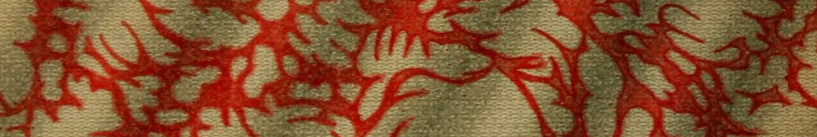
$3 x+4 x=4$ Ix $x$ sक

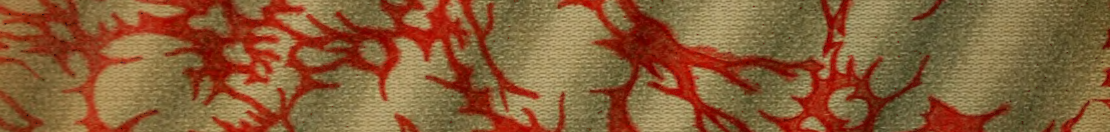

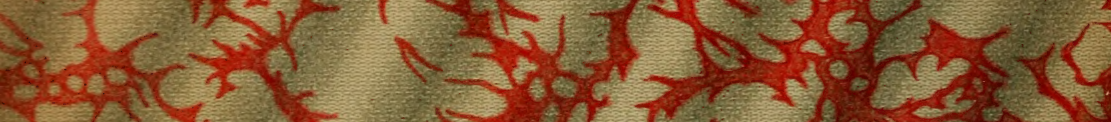
ary seg ta on सx

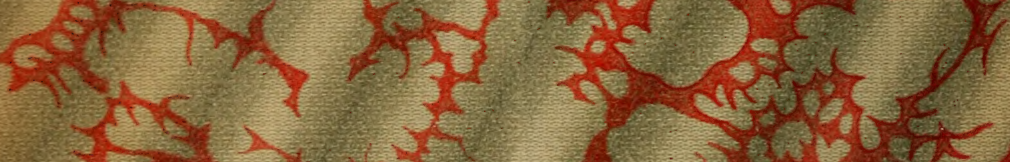

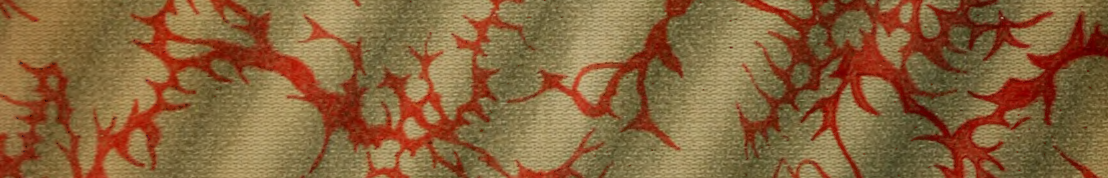
sulo.

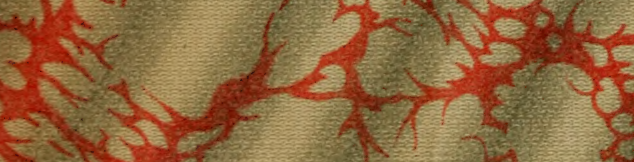

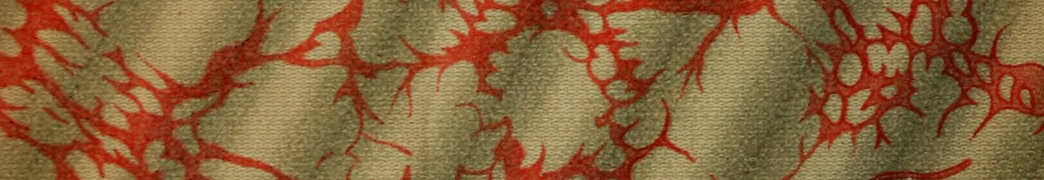

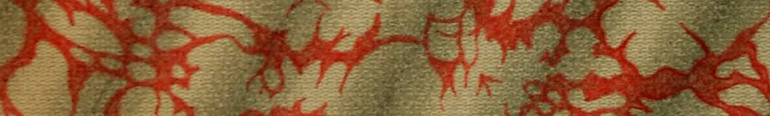
ma 

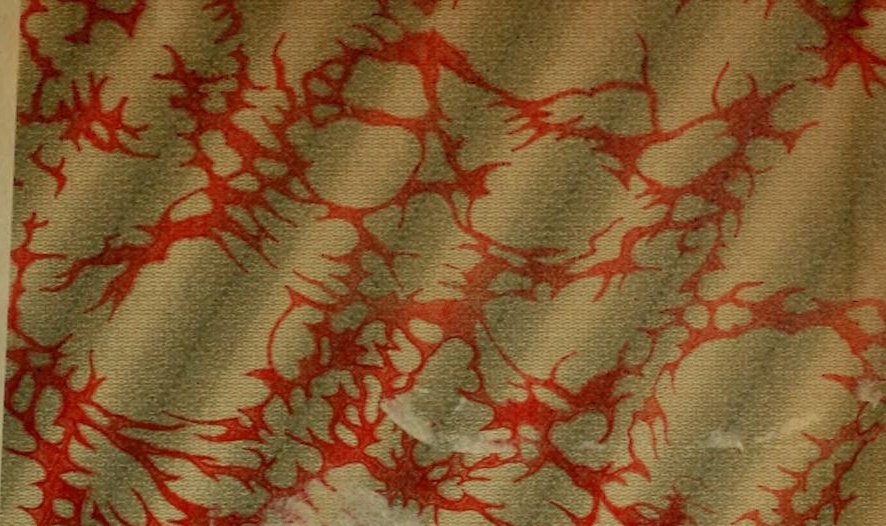

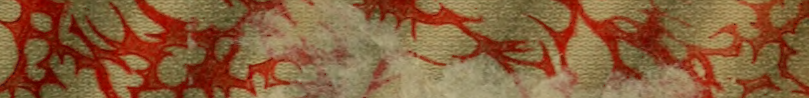
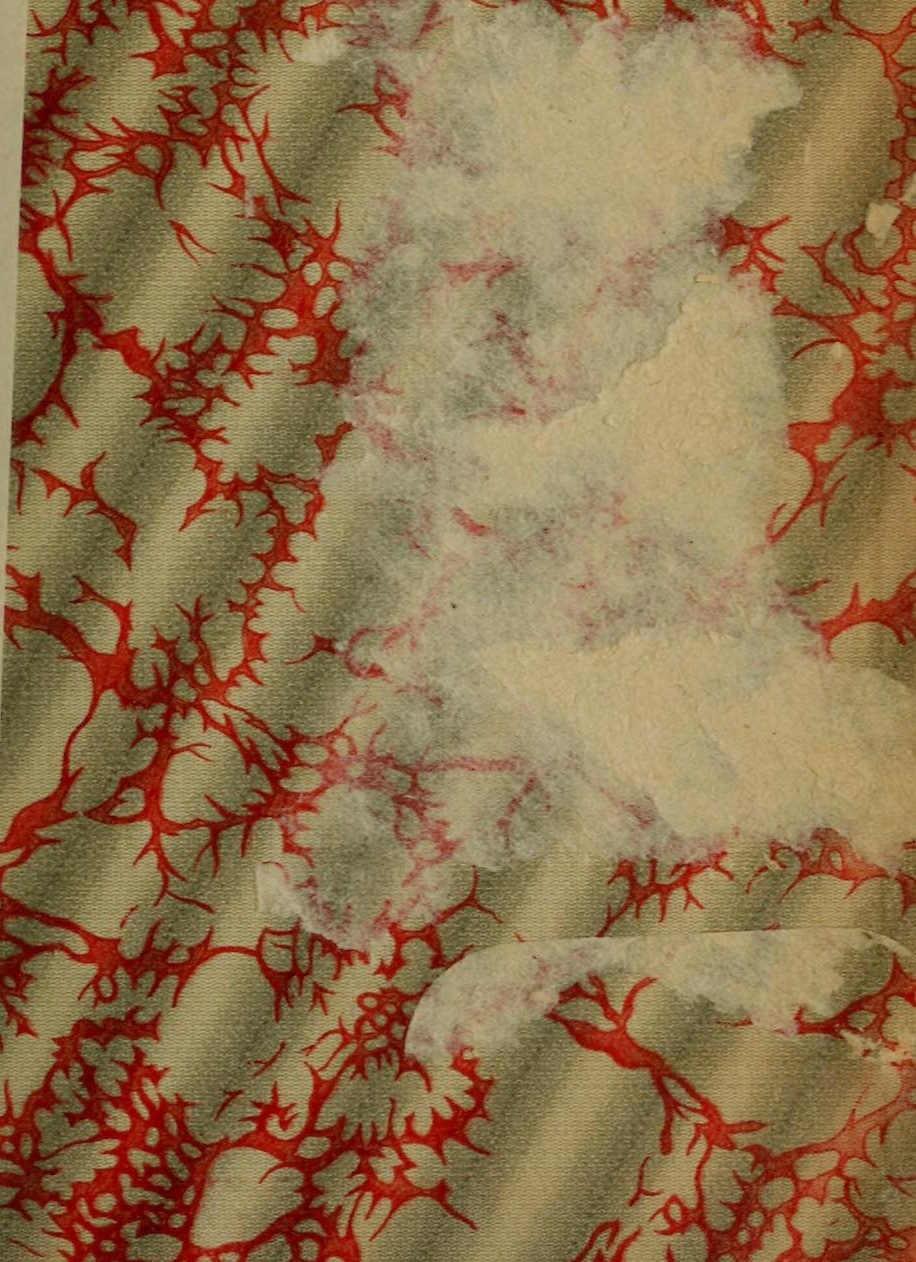
